\title{
Perceptual-motor styles
}

\author{
Pierre-Paul Vidal ${ }^{1,2}\left(\right.$ Francesco Lacquaniti $^{3,4} \mathbb{B}$
}

Received: 15 September 2020 / Accepted: 25 January 2021

(c) The Author(s) 2021

\begin{abstract}
Even for a stereotyped task, sensorimotor behavior is generally variable due to noise, redundancy, adaptability, learning or plasticity. The sources and significance of different kinds of behavioral variability have attracted considerable attention in recent years. However, the idea that part of this variability depends on unique individual strategies has been explored to a lesser extent. In particular, the notion of style recurs infrequently in the literature on sensorimotor behavior. In general use, style refers to a distinctive manner or custom of behaving oneself or of doing something, especially one that is typical of a person, group of people, place, context, or period. The application of the term to the domain of perceptual and motor phenomenology opens new perspectives on the nature of behavioral variability, perspectives that are complementary to those typically considered in the studies of sensorimotor variability. In particular, the concept of style may help toward the development of personalised physiology and medicine by providing markers of individual behaviour and response to different stimuli or treatments. Here, we cover some potential applications of the concept of perceptual-motor style to different areas of neuroscience, both in the healthy and the diseased. We prefer to be as general as possible in the types of applications we consider, even at the expense of running the risk of encompassing loosely related studies, given the relative novelty of the introduction of the term perceptual-motor style in neurosciences.
\end{abstract}

Keywords Redundancy $\cdot$ Adaptation $\cdot$ Plasticity $\cdot$ Variability

\section{Introduction}

Goal-directed movements, such as reaching, throwing, postural responses or locomotion, involve complex sensorimotor transformations that require the integration of multiple sensory inputs and the coordination of multiple motor outputs (Soechting and Flanders 1992; Massion 1994; Lacquaniti

Communicated by Patrick Haggard.

Francesco Lacquaniti

lacquaniti@med.uniroma2.it

Pierre-Paul Vidal

ppvidal@me.com

1 CNRS, SSA, ENS Paris Saclay, Université de Paris, Centre Borelli, 75005 Paris, France

2 Institute of Information and Control, Hangzhou Dianzi University, Hangzhou, China

3 Department of Systems Medicine, Center of Space Biomedicine, University of Rome Tor Vergata, 00133 Rome, Italy

4 Laboratory of Neuromotor Physiology, Santa Lucia Foundation IRCCS, 00179 Rome, Italy
1997; Ting and McKay 2007; Peterka 2002; Guerraz and Bronstein 2008; Carver et al. 2006). Given the complexity of these processes, it is not surprising that they almost never yield stereotypical responses, being instead associated with multiple solutions across repetitions and individuals even under identical initial conditions. Before considering the issues of variability and style, a few preliminary, relevant points must be considered.

First, there is the issue of redundancy. The number of degrees of freedom (DOFs) of our musculoskeletal system is very large. By assuming that there are 148 movable bones connected by joints in the human skeletal system and taking into account the kinematic constraints, the total estimated number of DOFs corresponds to 244 (Prilutsky and Zatsiorsky 2002). This number greatly exceeds the 6 DOFs required to place a body segment in a desired position with a desired orientation, for example when placing the hand over a computer mouse or the foot over a staircase step. Thus, given the redundant DOFs, there is an infinite number of different kinematic configurations of the body compatible with a given motor task. Moreover, since there are about 630 skeletal muscles in the human body, an average of 2.6 
muscles acts upon each kinematic DOF. Given that at least two muscles are available at each articular DOF, there is an infinite number of muscle force combinations that can produce a required joint torque (Prilutsky and Zatsiorsky 2002). The high redundancy of the musculo-skeletal system, coupled with the morpho-functional diversity of people (body height, mass, shape), makes it highly unlikely that any two different persons will adopt the same postural configuration for the same task under identical circumstances.

Secondly, behavior shows a great deal of adaptability driven by evolution. Our sensorimotor control cannot rely solely on an invariant repertoire of muscle responses. Stereotyped responses were not even sufficient when our distant ancestors lived in the aquatic environment some 400 million years ago.

Another relevant point concerns the plasticity of perceptual-motor responses following training or pathologies. Highly intensive training can profoundly alter our sensorimotor transformations to improve our performance in sports, for example. However, this does not guarantee that these changes are globally optimal in the long term, as the musculoskeletal injuries of joggers all too often demonstrate. In the same way, the occurrence of pathologies can profoundly alter motor responses and the underlying sensorimotor transformations. Therefore, individual longitudinal monitoring or follow-up of persons using quantitative approaches based on individual markers of behavior becomes imperative (Vidal et al. 2020).

Genetic differences between individuals, developmental stage, and age are other important factors that contribute to variability.

\section{Different kinds of behavioral variation}

Given the above premises, it is not surprising that sensorimotor behavior is typically characterized by a variety of implementation and expression solutions. Behavioral variety can occur along a continuum or it can involve discrete categories. Although the border between these two forms of variation is not always sharp, discrete categories are identifiable when measurable parameters allow clustering individuals or behaviors in different groups (e.g., Schorer et al. 2007; Maselli et al. 2019). Clustering requires that the individuals or behaviors belonging to the same group have parameter values more similar to each other than to those in the other groups. There is a wealth of statistical techniques for optimal clustering, such as those based on the comparison of within-cluster distances with betweenclusters distances (Gan et al. 2007). In addition, a variety of similarity measures are available to classify behavior and individuals (e.g. nearest-neighbor statistics, Van Der Maaten
2014), especially when the existence of clusters can be an unwarranted approximation.

\section{Variability}

Variability is ubiquitous but it takes different forms with different neural origin and different functional significance. Some of this variability is due to noise in neural spike trains, but some variability is principled. Variability in sensory estimation can be propagated through sensorimotor circuits, ultimately causing motor variability (Lisberger and Medina 2015). Each repetition of a motor action corresponds to a potentially different neural state, defined probabilistically within high-dimensional distributed networks (Shenoy et al. 2013).

Intra-individual, inter-trial variability due to various sources of noise (at the level of planning, execution or sensory feedback) is a fundamental characteristic of biological behavior and of the underling neural activity (Faisal et al. 2008). Even professional athletes -such as Major League baseball pitchers- exhibit trial-to-trial variability in their performance (Chaisanguanthum et al. 2014), although they tend to have more stable movement patterns than novices (Müller and Sternad 2004; Newell et al. 2006). The motor variability that interferes with performance is undesirable, and the central nervous system (CNS) may try to compensate for it by means of optimal control (Harris and Wolpert 1998; Todorov and Jordan 2002). The variability that does not interfere with performance but contributes to redundant control is not compensated (Lacquaniti and Maioli 1994; Scholz and Schoner 1999). One should also consider that behaviour can be learnt from two separate systems: one system creates habitual patterns based on past successful associations of actions with stimuli and context, and another system selects actions to best achieve a goal given the current stimuli and context (Robbins and Costa 2017). Practice promotes habit formation, and at the same, it modulates the likelihood of habit expression (Hardwick et al. 2019).

Variability can be more than just noise when people learn a new task and take advantage of inter-trial variability to explore the solution space by means of reinforcement strategies (Chaisanguanthum et al. 2014; Dhawale et al. 2017). Importantly, different subjects may show different levels of inter-trial variability during learning, which are consistent across movements and effectors, indicating the existence of individual traits. Thus, subjects with higher initial levels of task-relevant inter-trial variability tend to learn reaching tasks faster than subjects with lower inter-trial variability (Wu et al. 2014).

Individual hallmarks of this kind may underlie excellence in highly specialized skills such as those involved in sports or artistic performances (Yarrow et al. 2009). Age is also an 
important factor contributing to inter-individual variability. Thus, a recent study showed that elderly and young individuals rely on different aspects of motor variability to drive learning (Cheung et al. 2020). In the latter study, the score in a virtual bowling task correlated with the changes of timing variability of muscle activation in elderlies, while the score correlated with the variability changes of synergy magnitude in young adults. Notice further that, when the mode of rehabilitation training allows variability of limb trajectory, recovery from a lesion of the spinal cord is improved relative to training with a fixed trajectory (Ziegler et al. 2010).

\section{Style}

The kind of variability that tends to be associated with different individuals comes close to overlap with individual style. However, the variability of performance may be a transient feature of a specific behavior, while style refers to a relatively stable, consolidated feature of a behavior associated with a given context and developmental stage. Since most studies of sensorimotor variability describe features of behavior without considering whether these features are ephemeral or lasting, they may miss the identification of perceptual-motor styles in the sense we discuss in this review. However, it is quite likely that a number of instances of variability represent stable individual traits (e.g. Haar et al. 2017), and thus may be considered analogous to individual styles.

While the keyword of variability recurs quite frequently in the literature on sensorimotor behavior, the keyword of style is much less common in this realm. In fact, the notion of style is traditionally employed in the field of arts and entertainment to indicate the "how" a piece of work is realized, rather than the "what", "why", "when" or "where" (McMahon 2003). For instance, according to Fernie (1995), style is a "distinctive manner which permits the grouping of [artistic] works into related categories". Interestingly, the term style stems etymologically from stylus, the Latin word for an ancient writing utensil. With time, the metonymical usage of the term included the rhythm of handwriting independent of the written content and subsequently encompassed the artistic style in the general sense used today (Pinotti 2012). Therefore, style is historically rooted in sensorimotor control. Indeed, according to the art historian Ernst Gombrich (1998), "style is any distinctive, and therefore recognizable, way in which an act is performed or an artefact made or ought to be performed and made". Nevertheless, even in art history, the definition of style is not univocal. According to McMahon (2003), the term can be used to denote alternatively: (i) a period in history like the Early or High Renaissance; (ii) an artistic movement like Mannerism or Futurism; (iii) various developmental stages in an artist's oeuvre; (iv) the artist's point of view which may be ascertained from other than discernible properties in the artwork; and (v) a set of formal characteristics which cuts across periods, movements and individual oeuvres. The formal characteristics differentiate one artist's style from another one within a more general class, such as the impressionism (Fig. 1).

Operational definitions of style are still more difficult in physiology because its scientific inquiry requires objective, quantitative assessments. In principle, quantitative discrimination of styles depends on a wide (potentially unlimited) set of different parameters. In the following, we will consider different ways to identify perceptual-motor styles. It should be stressed that, just as in the case of arts and entertainment, also in physiology a given style is not necessarily unique to an individual, but it can be associated with different people according to the specific context, for instance when performing a given task or expressing a specific emotion. Only when a style is unique to an individual does it become a reliable biometric identifier, that is, a measurable behavioral feature
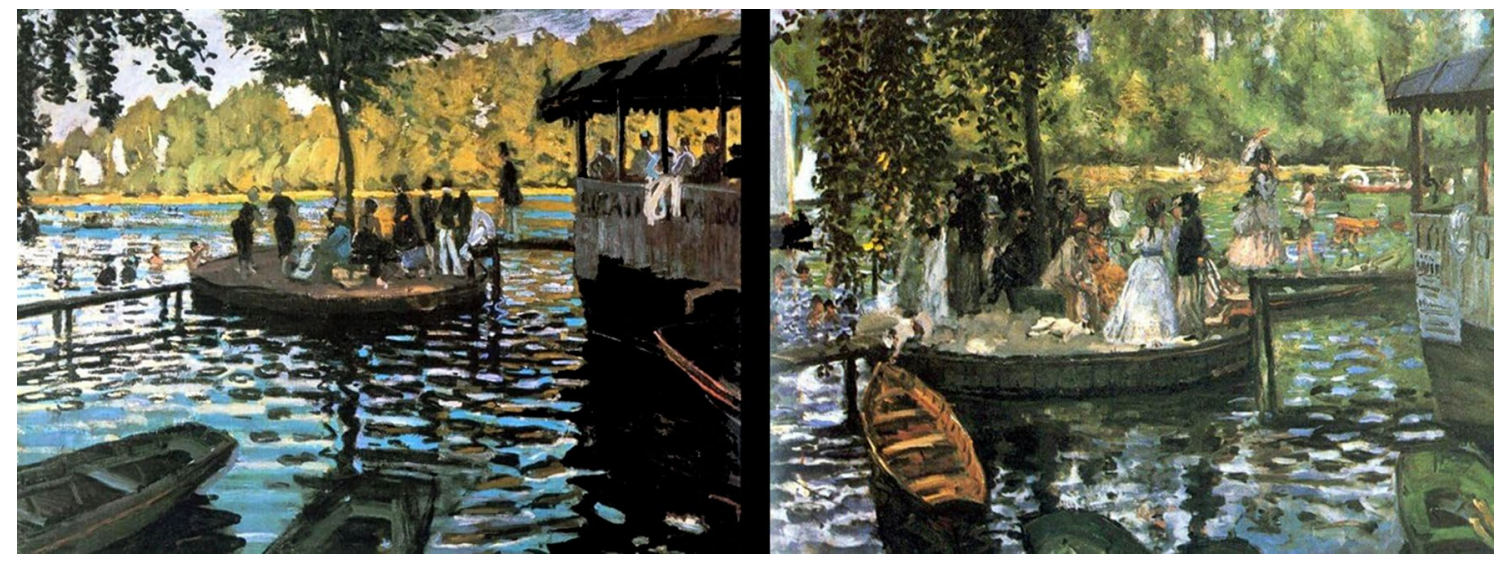

Fig. 1 La Grenouillère: same subject, two painters, two styles. The Frog Pond and Island were painted around the same time (1869) by the two friends, Claude Monet (left) and Pierre-Auguste Renoir (right) 
that can be used to label individuals. Notice, however, that in forensic science the concept of individuality is prudently taken in relative, not absolute sense since it is impossible to prove that a given human characteristic is unique to a given person without checking every other person in the world (Saks and Koehler 2008). The goal, then, is that of establishing individualization without claiming universal uniqueness (Kaye 2009). Furthermore, just as a given style can be associated with different persons, a given person may adopt different styles depending on the context or developmental stage.

In the following, we will retain the definition of perceptual-motor style as any distinctive and recognizable way in which an action is performed or perception is processed. This perceptual-motor style may be typical of a person, group of people, context, task or age. It may be determined genetically or as a result of development, learning, pathology. To be more comprehensive, we shall review both studies in which the term style was employed by the authors as well as studies in which the term of variability was used but, in fact, it referred to a phenomenology that would fall under the current definition of style. We do not claim to be exhaustive, since the pertinent literature would be potentially enormous, and we apologize for the inevitable omissions. At the end, we will consider some potential neural underpinnings of perceptual-motor styles.

\section{The sensory side}

\section{In healthy persons}

Witkin and collaborators were among the first scientists to use the term style in a perceptual-cognitive context (for a thorough review of cognitive styles in the context of psychology including an historical account, see Kozhevnikov 2007). To assess the subjective upright in space, Witkin and Asch (1948) introduced the Rod and Frame Test in which a rod and an external wireframe are rotated independently by variable angles. Based on the response to the test, subjects were classified into two distinct categories, each denoted as a specific cognitive style. Subjects who aligned the rod so that it leaned in the direction of the tilted frame were defined as field-dependent, since they relied on the visual field defined by the frame to judge the vertical. Instead, subjects who were able to align the rod close to the vertical independently of the wireframe orientation were defined as field-independent. To judge the vertical, the latter group of subjects relied more on vestibular and postural cues about the direction of the pull of gravity on the body. Since its introduction, the Rod and Frame Test has been used to assess perceptual-cognitive styles in several different conditions, from educational to sports and clinical contexts (e.g. Chan and Yan 2018; Evans et al. 2013).

Moreover, the pioneering results obtained by Witkin and collaborators with this text proved critical for the first elaboration of multisensory integration for the perception of the upright by Gibson (1952), who suggested that the visual vertical can be determined by a weighted combination of visual and postural cues. He argued that, in case of a discrepancy, the brain learns to use the reliable cues and to neglect the unreliable ones.

In fact, the existence of a sensory side of perceptualmotor style can be accounted for by the fact that several sensory systems are involved in generating an internal representation of the body in space and the perception of its own movement (Merfeld et al. 1999; Green and Angelaki 2010; Lacquaniti et al. 2014). Visual information determines the orientation of objects in space and the detection of body movements, including postural oscillations at rest (Lishman and Lee 1973; Prioli et al. 2005). Somatosensory information generated by muscle, joint and skin receptors encodes data on the relative position of the head, trunk and limbs in space (Barela et al. 2009; Allison et al. 2006; Jeka et al. 2000). Finally, vestibular information encodes the position as well as linear and angular accelerations of the head, thus helping to inform the brain of its orientation and movements in relation to space (Peterka and Benolken 1995). Continuous reweighting of these three types of sensory information is necessary for effective, flexible, and context-sensitive postural control, as shown in numerous studies (Mahboobin et al. 2005; Angelaki and Cullen 2008; Angelaki et al. 2009; Palluel et al. 2011; Block and Bastian 2011; Goodworth and Peterka 2012; Hwang et al. 2014; Assländer and Peterka 2014; Assländer 2016; Logan et al. 2014; Cyr et al. 2019; Dakin et al. 2020) conducted since the pioneering publication of Nashner (1976). The multi-sensory integrations that underlie our perception of our environment and our motor control are not simple algebraic additions of the sensory information available. Instead, they are based on a process of combining sensory inputs where the weight of each type of information is proportional to its relative reliability in a given context (Kabbaligere et al. 2017). For example, if a person uses cutaneous information generated by the sliding of the hand in contact with a fixed surface to learn about her/his body movement, it is this haptic information that will determine the assessment of her/his own movement as a priority (Harris et al. 2017). This explains why even minimal tactile cues are so effective in maintaining postural stability (Oie et al. 2002; Honeine 2015).

However, sensorimotor transformations and their weightings in contexts of sensory conflict or simply in unusual contexts can be difficult to interpret. Static equilibrium is usually quantified by oscillations of the center of pressure (COP) within the base of support. Increased variability of 
the COP, as well as an increase in its excursion and velocity are often considered an alteration of postural control. Nevertheless, these same COP oscillations may reflect an exploratory mechanism, necessary to provide increased feedback to the CNS (Schieppati et al. 2002). Methods used for analyzing random-walk-like stochastic patterns have been applied to COP trajectories to understand individual differences in quiet stance (Maurer and Peterka 2005). It should also be noted that the individual characteristics of static posture at rest do not allow us to prejudge the course of compensatory postural adjustments caused by a postural perturbation (Moya et al. 2009; Sell 2012). In this vein, the results of studies performed on postural control in space indicate a strong heterogeneity among astronauts in the adaptation of their perceptual-motor style to microgravity: their sensitivity on the plantar sole increases, which seems logical since vestibular information is profoundly modified, but static postural control is not correlated with this increase (Strzalkowski 2015). Similarly, contrary to what might be expected, vection sensitivity and latency are not uniformly modified in astronauts (Mueller et al. 1994; Oman et al. 2003).

\section{In disease}

Again, the interpretation of increased COP movement in pathology may be indicative of either a deficit in static postural control or an attempt to increase sensory feedback, or both. The same problem therefore arises, but with greater acuity since the clinician will adopt radically different rehabilitation strategies depending on the interpretation (Geurts et al. 2005).

\section{Vestibular pathologies}

The abundance of literature on the subject of vestibular compensation does not allow an exhaustive discussion of the subject in this article. Numerous reviews have been written on the subject (Thigilet et al. 2019; Lacour et al 2016) and their rehabilitation (Sulway and Whitney 2019; Sienko et al. 2018) to cite the most recent. The reader is referred to these for a more in-depth study of the topic. We will limit ourselves here to addressing the problem of weighting sensory inputs during a vestibular deficit. As early as 1982, Nashner et al. pointed out that the main problem for patients with vestibular deficits was their inability to weigh sensory information. In other words, these patients would be handicapped not so much by the loss of vestibular information as by their inappropriate responses to proprioceptive and visual information. Nashner concluded that vestibular information provides a necessary internal frame of reference for the interpretation of visual and proprioceptive afferents, a conclusion supported by a study by Creath et al. (2002).
It is also well established that vestibular deficits can lead to increased sensitivity to visual (Cheung et al. 1989) and proprioceptive stimulation of the lower limbs (Faralli et al. 2009). An interesting question is the dynamics of this visual prevalence as a function of the dynamics of loss of vestibular afferents. An abrupt loss of vestibular afferents would be less likely to cause a strong visual dependence than a progressive loss. Conversely, postural deficits would be more accentuated (Tjernström et al. 2018). The nature of the vestibular lesion also has an influence on the vestibular syndrome (Magnusson and Padoan 1991) as well as the activity of the person (Parietti-Winkler et al. 2016).

\section{Pathologies of the somatosensory system}

Proprioceptive afferences from the plantar side of the feet naturally play an important role in postural and locomotor control. A study by Pasma et al. (2012) shows that proprioceptive information from each leg is independently weighted according to its reliability. The contribution of proprioceptive information is clinically assessed by testing static postural control on foam mats (Schut et al. 2017). When proprioceptive afferents are impaired, is the vestibular information sufficient to control static posture? The answer is yes: in a subject with sensory polyneuropathy that resulted in a significant loss of positional awareness of her whole-body, Blouin et al. (2007) observed that sitting posture without back or arm support was maintained when the eyes were closed and both legs were dangling. Subjects with peripheral neuropathies respond much more strongly to galvanic vestibular stimulation than healthy subjects (Day and Cole 2002; Horak and Hlavacka 2001). Also, during peripheral neuropathies, compensation strategies differ considerably from one subject to another (Bunday and Bronstein 2009). Finally, it is relevant that adolescents with idiopathic scoliosis have difficulties in weighting sensory information (Simoneau et al. 2006), as is the case with vestibular patients (Nashner et al. 1982).

\section{Stroke}

Stroke patients are highly visually dependent (Corriveau et al. 2004; Bonan et al. 2004, 2006, 2013, 2015; Yelnik et al. 2006; Tasseel-Ponche et al. 2017). This visual dependence is also accompanied by an increased sensitivity to proprioceptive and vestibular information (Marsden et al. 2005). Studies on the weighting of sensory input following stroke also demonstrate significant inter-individual variability between patients (Bonan et al. 2013, 2015). Some subjects are insensitive to sensory stimuli, while others have static postural control that is highly impacted by one, two, or three types of stimuli. Between these two groups, many patients are moderate responders (see Fig. 2). 

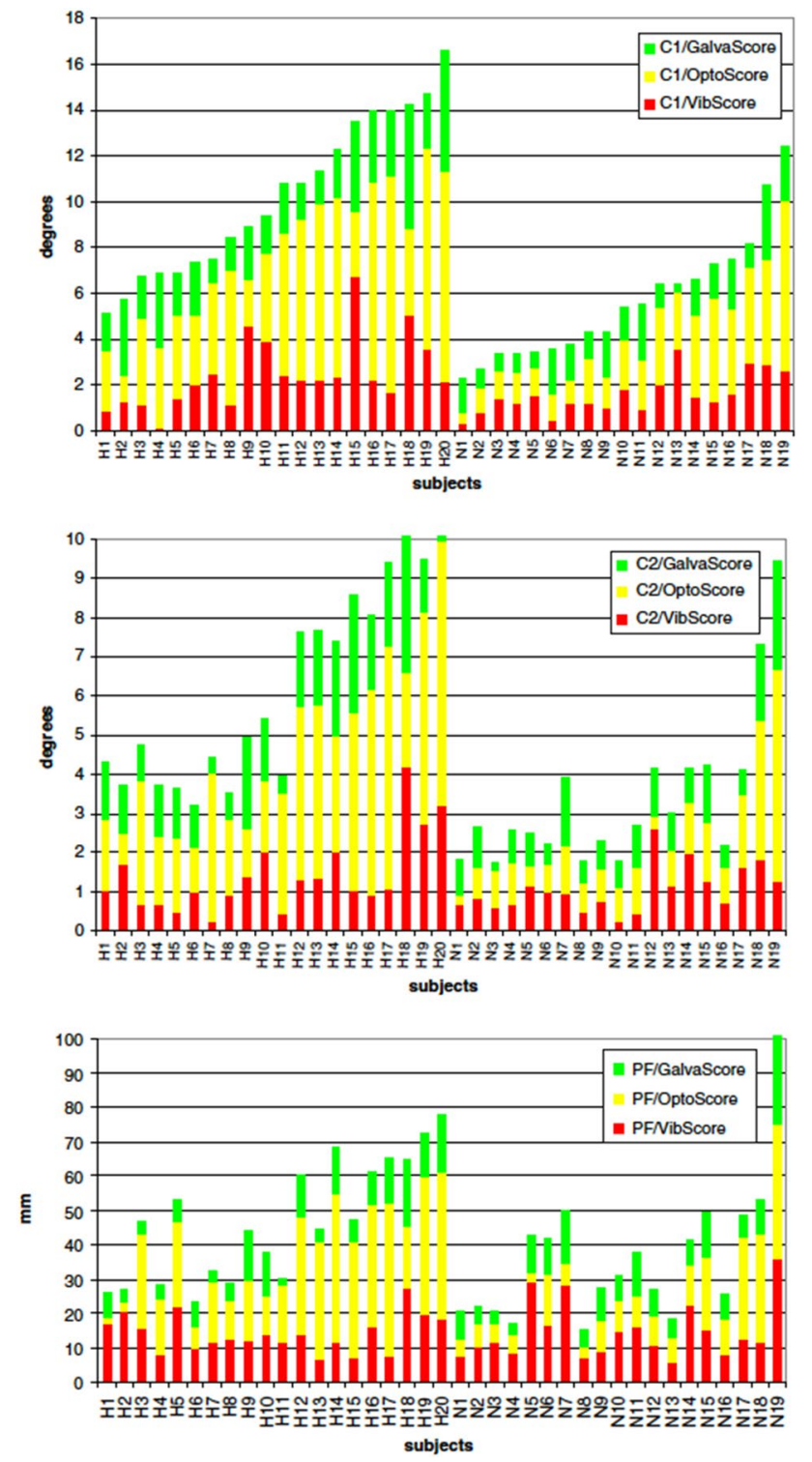

Fig. 2 Interindividual variability of the responses to sensory stimulations in control and stroke patients. Composite scores (in degree or $\mathrm{mm}$ ) of different subjects during optokinetic (red), vibratory (blue) and galvanic (green) stimulations recorded by the inertial sensor placed on the head (top panel, C1), trunk (middle panel, C2) and the platform (bottom panel, PF). The 20 hemiparetic subjects are labeled as $\mathrm{H} 1-\mathrm{H} 20$ and the control subjects as N1-N20). Modified with permission from Bonan et al. (2013)

\section{Conclusion}

Postural control is based on the generation of joint torques involving feedback loops (Alberts et al. 2016; Ravaioli et al. 2005; Peterka 2002; Peterka and Loughlin 2004; Kluzik et al. 2007; Cenciarini and Peterka 2006; Carver et al. 2005, 2006). A wide inter-individual variety of sensorimotor transformations seems to be the rule in both normal or pathological subjects, whether they involve postural responses to trunk acceleration (Vibert et al. 2001), to optokinetic stimulation (Sasaki et al. 2002), to eye closure (Lacour et al. 2016), or during the rod and frame test (Isableu et al. 2003). The instructions given to subjects also influence sensorimotor transformations (Fitzpatrick et al. 1992).

In congenital or acquired pathologies, structural and functional changes of the CNS are the rule. Whether this postlesional plasticity is beneficial remains to be demonstrated. Indeed, it often appears pejorative for the functional prognosis, at least in the case of postural control. For example, although people suffering from congenital blindness present significant structural changes at the cortical level, their postural control remains deficient (Parreira et al. 2017 for a review on the subject).

This highlights the important role of training (Herssen and Mc Crun 2019) and rehabilitation in the case of sensory deficits to improve posture and locomotion control. Several studies suggest that a rehabilitation program based on visual deprivation could promote the use of somatosensory and vestibular afferents and thus reduce visual dependence (de Haart et al. 2004; Bonan et al. 2004; Di Fabio and Badke 1991). In addition, in the aftermath of a stroke, sensory stimulation can be used to normalize postural control and reduce the extent of postural deficits, including visual stimulation (Tilikete et al. 2001; Rode et al. 2006; Bonan et al. 2016), vestibular stimulation (Rode et al. 1997, 2005), and somatosensory stimulation (Pérennou et al. 1999, 2001; Pérennou 2006).

Notice that the concept of perceptual-motor styles has also proven useful in the analysis of performance in children with minimal brain dysfunction (Cakirpaloglu and Radil 1992). Thus, in a video-game, small and fast targets were often missed by brain-damaged children but not by healthy children. Also in this case, rehabilitation would benefit from visuomotor training protocols. In this respect, it has been shown that different stroke patients have different attention strategies during motor imagery rehabilitation (Sakurada et al. 2017). The ability to identify these individual strategies can therefore be useful in rehabilitation.

\section{The motor side}

Different kinds of movement features specific to an individual have been described from kinematic or kinetic data. Thus, it has long been known that the idiosyncratic shape of the signature of each person tends to be preserved through wide changes in execution size, speed and even effector (right or left hand, foot, mouth) and it is easily recognizable whether it is written with a pen on paper, with a stylus on a tablet, or a brush on a billboard (so-called motor equivalence). Since handwriting is highly individual, it can be used as a reliable biomarker (Plamondon and Srihari 2000). For 
instance, individual discriminability was determined at $98 \%$ confidence using macro-features of the handwritten text of 1500 subjects (Srihari et al. 2002).

In the following, we will use human gait as the main paradigm to illustrate critical movement features because much data exist for this behavior, but we will consider other examples of movements as well.

\section{Visual recognition of individuals}

As remarked at the outset of this article, individuals exhibit appreciable, often idiosyncratic variations in performing motor actions. These idiosyncrasies can be picked up perceptually even from limited visual cues. Thus, a common feeling is that we can recognize a familiar person from afar by looking at the way this person walks. It has been demonstrated objectively that recognition still occurs with very impoverished cues, in so far as viewers can recognize themselves and their friends from walking movements (Cutting and Kozlowski 1977) or arm movements (Hill and Pollick 2000) displayed as time sequences of point-lights corresponding to the main body joints (Johansson 1975). Recognition becomes chance-level when these animations are displayed in unusual orientations, such as upside-down (Loula et al. 2005). These abstract displays are devoid of familiarity cues, size and shape cues, or other non-kinematic sources of information. Biological motion stimuli such as those of point-light displays are interpreted by the brain based on local motion cues from the limbs, as well as on changing body configuration (Blake and Shiffrar 2007). These configural and motion cues are processed in dedicated brain regions, processed respectively in ventral and dorsal cortical pathways (Giese and Poggio 2003; Jastorff and Orban 2009; Maffei et al. 2015). A specific mechanism for action recognition has been suggested based on the discovery of mirror neurons in the ventral premotor cortex and a network of interconnected brain regions (Rizzolatti and Craighero 2004). The mechanism consists in the fact that, when we watch someone performing an action, our brain simulates the performance of the observed action (motor simulation theory). The mechanism hinges on the specific properties of visually responsive motor neurons, called mirror neurons. Thus, premotor cortex, parietal and occipitotemporal regions are activated in functional imaging studies when expert dancers view movements that they have been trained to perform (Calvo-Merino et al. 2005), or when naïve observers view silent video-clips of speech recorded in their familiar language as opposed to a non-familiar language (Maffei et al. 2020).

However, the features of visual motion that are used for individual human recognition are still incompletely understood. Pollick and Paterson (2008) remarked that style recognition requires first categorizing the movement type (walking, dancing, drinking, lifting, etc.), and then recognizing gender, ethnicity, age, emotion, identity. There is no single source of information about individual movement style, but a rich potential feature space available for recognition. Notice, however, that the perception of human identity and style is not always accurate since, in fact, it is often only slightly above chance-level (Cutting and Kozlowski 1977; Loula et al. 2005). However, this lack of accuracy does not necessarily imply that the information is not present in the animation per se. Unsurprisingly, recognition is much better when human movements are shown in full under natural viewing conditions, rather than as abstract point-light displays (O'Toole et al. 2011).

\section{Automatic video recognition of individuals}

The recent rapid developments of various techniques to monitor human movements on-line and cheaply have led to the proposal to use individual gait recognition as a biometric trait in several applicative fields beyond biomedicine (e.g., Boyd and Little 2005; Han and Bhanu 2005; Sprager and Juric 2015). The use of gait for human identification is still very recent as compared to methods based on fingerprints, voice, or face recognition. However, in contrast with other biometric variables, gait has the advantage of being difficult to imitate or camouflage. Moreover, it can be monitored remotely without the need for cooperation, contact or high image resolution. On the other hand, gait identification is made difficult by the presence of several confounding factors, such as variations due to walking speed, footwear, terrain, fatigue, injury, or passage of time. In addition, the caveat about the uniqueness of biometric parameters mentioned above naturally applies to gait parameters.

In automated surveillance and security scenarios, the ideal goal, not yet reached by current methods, would be to analyze the collected video data by means of machinelearning algorithms, detect abnormal behavior, determine the identities of all persons in the scene, track the suspects, and warn before an adverse event happens (Zhang et al. 2011). Current gait recognition techniques rely on the analysis of spatial and/or temporal features (Zhang et al. 2011). Spatial features can be processed using Linear Discriminant Analysis to reduce the dimension of the accumulated feature vector. Since humans recognize the gender of a person from point-light displays of her/his gait and since upper and lower halves of the body provide different contributions (Barclay et al. 1978), spatial processing involves dividing the averaged body silhouette in different body parts and using Support Vector Machine to train the classification weights of all the parts. Temporal features can be processed using Principal Component Analysis (PCA) and Multiple Discriminant Analysis projection to represent individual characteristics in a low-dimensional space and then training a nearest 
neighbor classifier for identification (Zhang et al. 2011). Deep recurrent neural networks can be trained to detect long-term temporal dependencies for the re-identification of individual gaits (Wu et al. 2016). Notice, however, that the issue of automated surveillance is currently under scrutiny due to the critical ethical considerations raised by the identification of individuals, as well as the potential gender and ethnic biases inherent in some techniques.

\section{Individual features of movement}

\section{Gait}

It has long been known that healthy individuals show considerable differences in walking, even when speed and footwear are controlled (Winter 1988; Simonsen and Alkjær 2012). The individuality principle states that individuals exhibit different motor styles that depend on genetic, developmental and learning processes (Ting et al. 2015). Individual gait features can be identified by means of pattern recognition tools, such as those used in computer gait analysis (see above). A reliable individual characterization requires very large samples of subjects as well as test/retest protocols to verify the persistence of a given feature within individuals at different times, but these criteria are often difficult to satisfy. Two studies examined $>100$ walking subjects and re-tested a subsample of these subjects a few months (Horst et al. 2017) or years apart (Pataky et al. 2012). These studies succeeded in identifying accurately (classification rate $>99 \%$ ) the participants based on either plantar pressure (Pataky et al. 2012) or ground reaction force patterns (Horst et al. 2017). Deep artificial neural networks have been used to identify these individual gait patterns reliably (Horst et al. 2019). Hug et al. (2019) were able to label accurately individuals based on the electromyographic (EMG) activity patterns of eight muscles of the lower limbs during gait and pedaling. Avrillon et al. (2018) found that the distribution of activation among the heads of the hamstring muscles is individual-specific.

Another individual feature of walking has been described by considering the intersegmental kinematic coordination. The changes of the elevation angles of the lower limb segments covary along a plane (Borghese et al. 1996; Bianchi et al. 1998). This kinematic law is very robust since it has been confirmed in many animal species in addition to humans, in different laboratories and experimental settings (see Catavitello et al. 2018). However, plane orientation (which depends on intersegmental phase) at any given walking speed has been shown to differ systematically across a sample of 24 healthy human subjects, correlating with the individual expenditure of mechanical energy (Bianchi et al. 1998). In general, the faster we walk, the greater the energy expenditure. The phase coupling between shank and foot provides a compensatory mechanism to reduce the energy fluctuations. However, not all subjects are the same. As shown in Fig. 3, trained subjects (yellow) exhibit a more pronounced phase shift of planar covariation as compared with untrained subjects (red). As a result, trained subjects climb the energy mountain along a less steep, more advantageous path. Interestingly, virtually grafting the kinematics of an energy-saving subject into the body of an energy-hungry subject can save up to $50 \%$ of energy in the computed chimera, whereas the opposite (grafting the body of energysaving subject into the kinematics of energy-hungry subject) does not lead to any saving in the computed chimera (Bianchi et al. 1998). This shows that kinematics is more critical to determine energy expenditure than anthropometric factors such as mass distribution.

A recent study aimed to identify markers defining a person's motor style during posture and locomotion (Mantilla et al. 2020). The hypothesis was that the markers should have two characteristics: first, they should exhibit idiosyncratic features, i.e. they should have the lowest possible intra-individual variability; second, they should be as

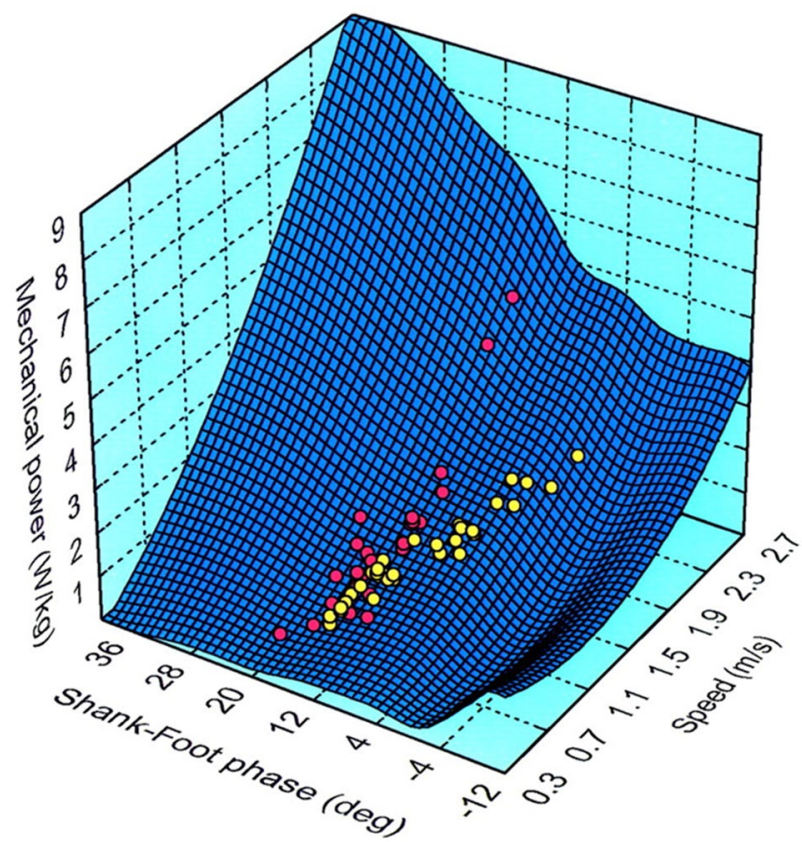

Fig. 3 Individual characteristics of walking mechanics. Mass-specific mechanical power is plotted versus walking speed and phase between shank and foot elevation. The curved surface fits the results from 24 different subjects walking at speeds between 0.4 and $2.6 \mathrm{~m} / \mathrm{s}$. Individual data from 2 subjects are plotted with different colors: yellow, a trained subject with a pronounced phase shift with increasing speed, red, an untrained subject with a much less pronounced phase shift. Note that the mechanical power output at intermediate and high speeds is correspondingly lower in the former than in the latter. Modified with permission from Lacquaniti et al. (1999) 
different as possible between individuals, i.e. they should have the greatest possible inter-individual variability. A person's motor style may affect all of a person's motor activities, but Mantilla's study was limited to markers that characterized resting postural control and locomotion, behaviors that are regularly scrutinized in the clinic.

Locomotion includes progression towards a goal (navigation), the generation of musculoskeletal patterns to achieve this (dynamic components) while maintaining a stable posture in different environments (static components). Many markers are therefore available to capture the different facets of the style during walking and running. The choice focused on the study of the configuration of the body in the sagittal plane (Fig. 4) and on four dynamic parameters, explored in the transverse (horizontal), sagittal and frontal planes: a measure of the fluidity of the movement expressed by jerk (second time derivative of velocity), a measure of its variability (root-mean-square deviation, RMS), a measure of its regularity estimated by entropy, and a measure of optimization of the trajectory inferred by the relationship between the curvature of movement and its tangential velocity (the twothirds power law, Lacquaniti et al. 1983). The results confirmed that at rest and during locomotion, motor control in humans can be broken down into two components. A static component is defined by the stable configuration adopted by a given person to position their head, trunk and limbs in relation to gravity. A dynamic component characterizes the relative movements of the head, trunk, arms and limbs. By quantifying and comparing these static and dynamic components, the study was able to identify the set of markers defining motor style during posture and locomotion. They are listed in Table 1. The identification of individual markers of gait has recently been shown to help detecting steps in individuals with severely altered gait due to Multiple Sclerosis (Vienne-Jumeau et al. 2020). A still unresolved issue, however, is whether the individual features of motor style remain stable across the lifespan or change, since several motor control parameters undergo wide changes in one person's life.

\section{Eye movements}

Individual motor signatures have also been uncovered for eye movements (e.g., Ettinger et al. 2003; Smyrnis 2008). In a recent study, a 21-dimensional vector of performance metrics of 1058 participants was computed for video-based eye-tracking tasks involving pro-saccades, anti-saccades, and smooth pursuit (Bargary et al. 2017). The biometric parameters were able to identify the oculo-motor signatures of individual participants as shown by re-testing a randomly selected subsample $(n=105)$ of the participants about 20 days after the first session. The importance of biometric parameters of eye movements is also underlined by a study involving eye-tracking of visual targets bouncing back and forth under gravity or artificial reversed gravity (Meso et al. 2020). Grouping participants by high or low traits of schizotypy -assessed by a standard personality questionnaireshowed a negative relationship between schizotypy traits level and both initiation and maintenance of eye-tracking, a result consistent with trait-related impoverished sensory prediction. Divergence of performance between the two groups was especially high for tracking gravity-incongruent targets (Meso et al. 2020).

\section{Arm movements}

Interception of fast targets, such as a tennis serve or a baseball pitch, requires efficient processing of incoming visual information along with prior models of the throw and programming the appropriate response. There are very large differences across individuals in the sensitivity to different types of dynamic visual cues. For instance, Regan and Beverley (1979) found an 80:1 range in the relative sensitivity to retinal dilatation rate and binocular disparity across five tested subjects. Both motion planning and execution are influenced by sensory-motor noise in a highly subjectspecific manner (Zago et al. 2009). Thus, systematic differences in several kinematic parameters of interception movements have been reported across naïve subjects reflecting different interception styles (Cesqui et al. 2012; La Scaleia et al. 2015). In one study (Cesqui et al. 2012), participants had to catch on the fly a ball projected by a motorized apparatus with different launch parameters, resulting in different arrival flight times and height conditions. A subset $(n=6)$ of all participants exhibited quite comparable interception performances, and nevertheless, their arm and hand movements differed drastically in several parameters, such as wrist trajectory, wrist velocity profile, timing and spatial distribution of the impact point, upper limb posture, trunk motion, and sub-movement decomposition. Importantly, the individual behaviours were consistent across two experimental sessions carried out at 1-year distance. In a different study (Golenia et al. 2014), the participants learned to pick up a wooden cylinder with different kinds of pliers, a difficult task. The tool grasping profiles of different individuals differed, as did the learning curve during practice.

Fast and efficient visual decoding of throwing styles is especially critical in ball games (e.g. baseball, cricket, etc.). Fast balls afford very little time to process visual information about the trajectory of the approaching ball, given the conspicuous visuomotor delays (Zago et al. 2009). Thus, a $200 \mathrm{~km} / \mathrm{h}$ tennis serve or a $150 \mathrm{~km} / \mathrm{h}$ fastball in baseball leave less than $500 \mathrm{~ms}$ to the receiver to react, but the brain takes about $250 \mathrm{~ms}$ to process ball motion and move accordingly. In fact, sport science has shown that expert players can pick up advance information 

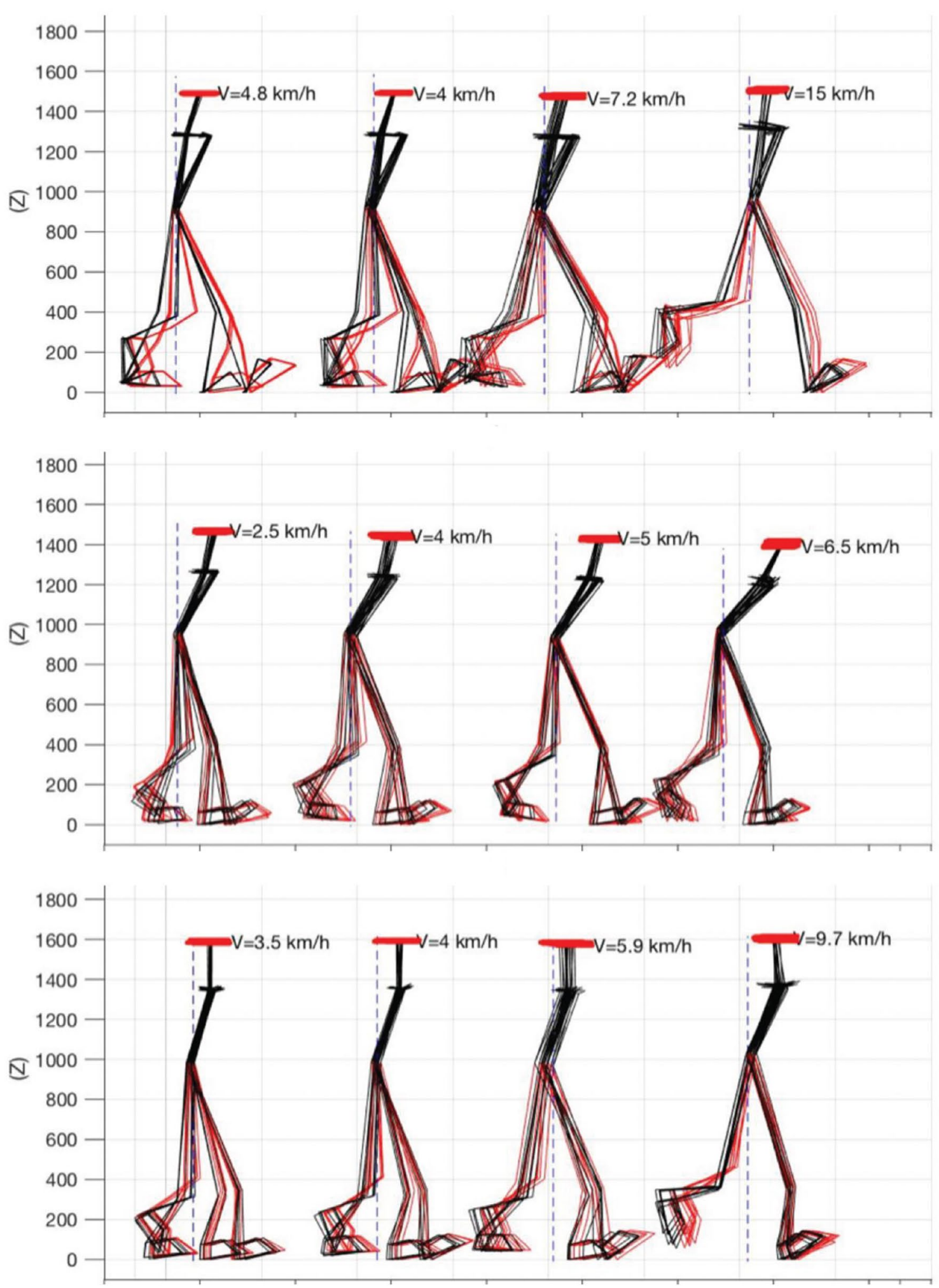

Fig. 4 Stick diagrams depicting postural configurations of three subjects (from topo to bottom) in the sagittal view. From left to right: comfortable walk, walk at $4 \mathrm{~km} / \mathrm{h}$, race walking and running. Bold red horizontal bars indicate head excursion, while the other lines indi- cate trunk and leg motions. The configurations have been acquired at the time of heel strike for each foot (red and black overlapped leg configurations). Modified with permission from Mantilla et al. (2020) 
Table 1 Summary of features defining motor style during posture and locomotion

\begin{tabular}{|c|c|c|c|c|c|c|c|c|c|c|c|c|}
\hline & \multicolumn{4}{|c|}{ Frontal } & \multicolumn{4}{|c|}{ Sagittal } & \multicolumn{4}{|c|}{ Transverse } \\
\hline & Head & Trunk & Legs & Feet & Head & Trunk & Legs & Feet & Head & Trunk & Legs & Feet \\
\hline Inclination at rest & & & & & + & + & & & & & & \\
\hline Inclination for locomotion & & & & & + & + & & & & & & \\
\hline Jerk locomotion & & + & + & & & & & & & & & \\
\hline RMS locomotion & & & & & & & & & + & + & & \\
\hline Entropy locomotion & & & + & + & + & + & & & + & + & & \\
\hline
\end{tabular}

Crosses indicate statistically significant inter-individual differences

about the forthcoming ball trajectory and velocity from the observed throwing action of their opponent (Muller et al. 2006; Abernethy et al. 2008; Aglioti et al. 2008), so as to optimize their interception/catching performance (Mann et al. 2010). Indeed, the thrower often tries to limit the involuntary information provided to the receiver by concealing her/his throwing direction.

Maselli et al. (2017) assessed which parameters of whole-body kinematics of the thrower best correlate with the direction of a thrown ball. To this end, they recorded the throwing actions of 20 non-experts asked to hit one of four targets at $6 \mathrm{~m}$ distance. By using dimensionality reduction and machine learning techniques, they found that the throwing arm provides accurate information about the outgoing ball trajectory, but only in the very last phase of the throwing action, at 100-200 ms before ball release. At earlier times prior to ball release, the trunk and the upper and lower limbs contralateral to the throwing arm provide informative cues. This study also detected differences in throwing styles across the sample of throwers, with corresponding inter-individual differences in the spatio-temporal structure of the thrower's predictability. For most participants, fairly accurate predictions of where in space the ball will land could be reached as early as 400-500 ms before ball release from the hand.

The individual throwing strategies were specifically investigated by Maselli et al. (2019). They found that the identity and gender of the thrower could be reliably inferred from the kinematics of a single throw. In particular, cluster analysis identified four main classes of throwing strategies (motor styles), which were very consistent within individuals. The four styles consisted in no-step, right-step, left-step, and double-step prior to the throwing arm gesture, these stepping movements taking place at various times prior to the throw (Fig. 5). Interestingly, these styles were reminiscent of the throwing modes exhibited by children during the main stages of proficiency acquisition during motor development (Wild 1938; Roberton et al. 1979). Thus, the results support the idea that inter-individual and gender differences in skilled behaviour, such as throwing, are related to skill acquisition interrupted at different stages of the typical developmental trajectory of the specific motor behaviour. However, these results are still preliminary and we still do not know whether the different styles are correlated with a different performance success.

Hilt et al. (2016) reported large inter-subject variability as compared with intra-subject variability in whole-body reaching movements towards a surface. They found that individual motor styles spanned a continuum between the two extreme patterns of ankle and knee strategies. Hilt and colleagues were able to account for the idiosyncratic behaviours by means of individual combinations of different optimality criteria, involving mechanical energy expenditure, joint smoothness and minimization of the amount of torques. Słowiński et al. (2016) identified individual motor signatures in freehand movements by clustering the distances between the velocity profiles of different participants. They further showed that coordination between two individuals performing a joint-action task was higher if their motions shared similar dynamic features. However, there are conditions under which participants cannot avoid (unintentionally) coordinating with someone else, and to do so they must give up their original movement pattern (Issartel et al. 2007).

A recent study (Sternad 2018) points out that variability in motor performance represents both a nuisance and an advantage. On the nuisance side, aging by causing changes in both musculoskeletal, vestibular, and visual receptors can increase variability in gait, leading to instability and falls (Herssens et al. 2018; Kikkert et al. 2016; Ayoubi et al. 2015), particularly in frail elderly people (Schwenk et al. 2014; Dasenbrock et al. 2016; Mortaza et al. 2014; Herssens et al. 2018). The variability of gait also increases during various pathologies (Figueiredo et al. 2018) such as cerebellar and vestibular ataxia (Schniepp et al. 2017; Buckley et al. 2018) and neurological disorders with motor deficits (Ivanenko et al. 2013; Moon et al. 2016).

However, variability in motor performance can also be an advantage and depends in particular on the structure of the motor task. Motor components that contribute directly to the task often show little variability, while components that do not contribute tend to be more variable, thus reducing the adoption of different speeds leading to changes in the 


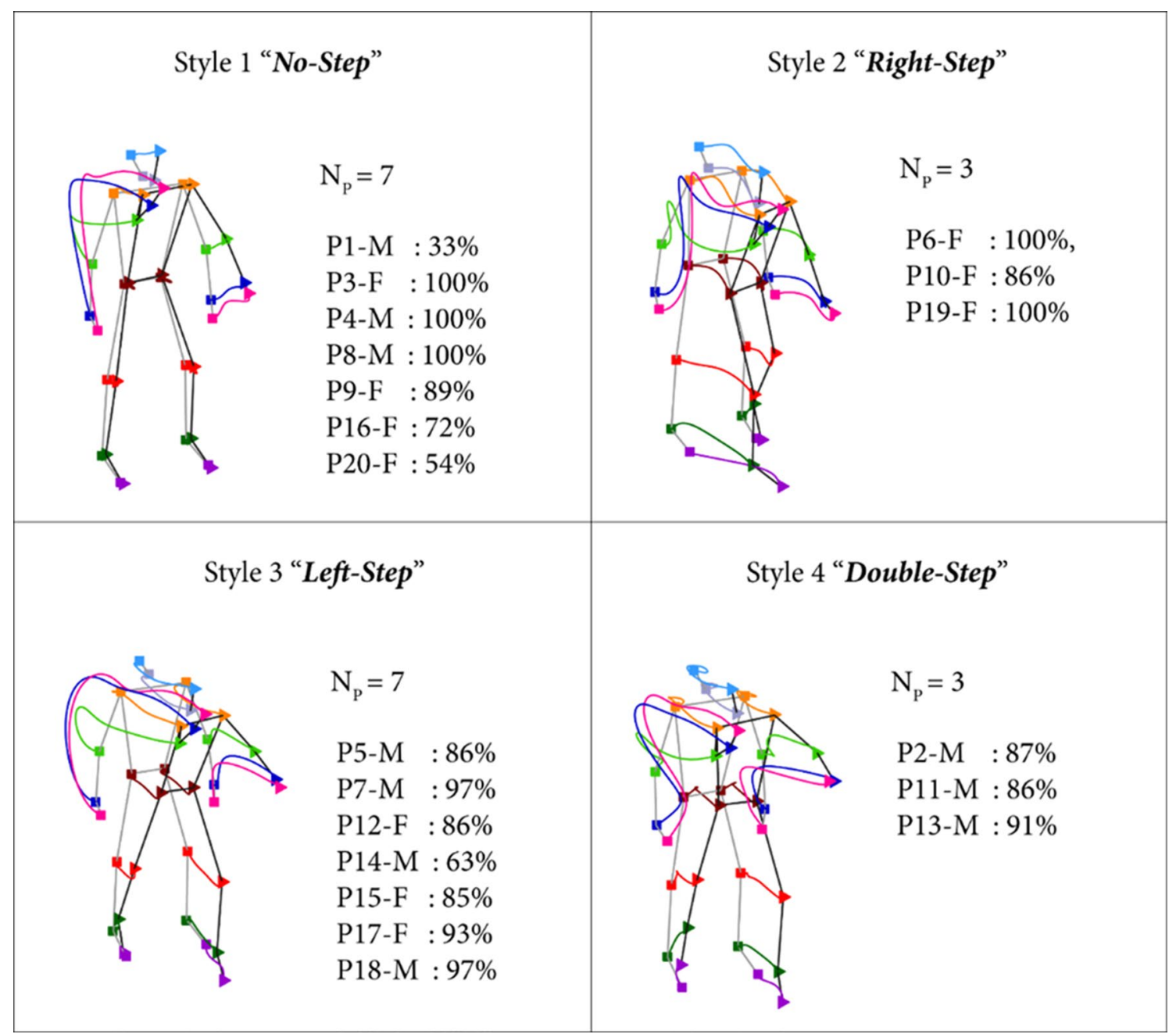

Fig. 5 The four typical throwing styles emerging from cluster analysis. Each panel shows the mean throwing trajectories averaged across all trials assigned to the corresponding cluster, independently of the individual thrower. Different colors correspond to different joint markers. Throwing styles can be adopted by different throwers. Each

variability of the components of the stride, changes that have an adaptive value (Dingwell and Cusumano 2015; Dingwell et al. 2017, Möhler et al. 2020). In addition, as a comparison between experienced and novice runners shows, variability during the stride could reduce the risk of injury (Mo and Chow 2018; Hamill et al. 2012). Variability may also specifically contribute to the acquisition of novel perceptual-motor behaviours, such as when walking on a split-belt treadmill (Van de Putte et al. 2006, Altman et al. 2012) or on a narrow beam (Sawers et al. 2015), as well as during pathologies that affect the locomotor system (Mawase et al. 2016). Finally, the variability of several parameters during walking are good indicators useful for the study of sensorimotor development (Kraan et al. 2017).

The studies reviewed above show that humans exhibit various styles of perception and motor behavior, which are panel further reports the number of participants for whom the highest fraction of throws is assigned to the corresponding style $\left(N_{\mathrm{P}}\right)$, the participant identity (P1-P20) and gender (M, F), and the fraction of throws that is assigned to that specific throwing style represented in the panel. Modified with permission from Maselli et al. (2019)

based on inter-individual variations in the way they treat sensorimotor transformations. In this context, the characterization and monitoring of the perceptual-motor style are important for several reasons. First, predictions are important for monitoring many aspects of human behavior when individuals interact with each other. This requires prior knowledge of relevant sources of information to make reliable predictions about the behavior of others, predictions that vary according to the perceptual-motor style of the person with whom one interacts (Maselli et al. 2019).

Second, differences in perceptual-motor style, since they are idiosyncratic, can be more or less efficient, raising the question of when they need to be adjusted to maintain optimal control (see Moore 2016 for a review of the economy of walking and running). Third, changes in a person's 
perceptual-motor style could reveal the beginning of a pathological process and help to track their recovery (König et al. 2016).

\section{Style may depend on age}

Manipulation of sensory information induces postural changes even in infants, and this ability to use sensory information increases up to ten years of age (Delorme et al. 1989), Higgins et al. 1996; Barela et al. 1999; Bertenthal et al. 2000; Barela et al. 2000, 2003; Schmuckler 1996; Godoi and Barela 2008) and even beyond (Godoi and Barela 2008, Peterson et al. 2006; Sparto et al. 2006; Zernicke et al. 1982). Infants and children, however, have more difficulty in resolving sensory conflict situations correctly and may even fall (Lee and Aronson 1974; Forssberg and Nashner 1982; Stoffregen et al. 1987). In particular, children under the age of 7 years have difficulty integrating sensory information correctly and favor visual information (Lee and Aronson 1974; Forssberg and Nashner 1982; Rival et al 2005; Shumway-Cook and Woollacott 1985; Wolff et al. 1998; Woollacott et al. 1987) but this dominance is open to debate (Barela et al. 2003, Godoi and Barela 2008; Metcalfe et al. 2005; Peterson et al. 2006; Bair et al. 2007). Children, to a certain extent, would be able to weight sensory information to control their posture (Barela et al 1999, 2000 2003; Schmuckler 1997; Polastri and Barela 2013). However, these adaptations have their limits below 12 years of age (Lee and Aronson 1974; Butterworth and Hicks 1977; Forssberg and Nashner 1982; Wann et al. 1998; Rinaldi et al. 2009; Polastri and Barela 2013). Using portable devices, a few studies explored the motor signatures of developmental disorders, such as autism (Jansiewicz et al. 2006; Anzulewicz et al. 2016).

As remarked above, elderly and young individuals learn a task by taking advantage of different aspects of motor variability (Cheung et al. 2020). As we age, the sharpness of our senses diminishes, and this can affect our lifestyle. To compensate for this deterioration, the brain reweighs the sources of sensory information according to their signal-to-noise ratio. Numerous studies suggest that the degeneration of the vestibular system (Rosenhall and Rubin 1975) and the accompanying decrease in the signalto-noise ratio of vestibular information may explain the preponderance of visual information during aging (Anson and Jeka 2016; Jeka et al 2006; Alberts et al. 2019) and in accompanying pathologies (Bronstein et al. 1996; Bronstein 1999; Guerraz et al. 2001; Lopez et al. 2007; Grabherr et al. 2011). This process of reweighting sensory information in favor of visual inputs would include the estimate of the vertical direction (Curthoys 2000; Peterka 2002; Peterka and Loughlin 2004). This primacy of visual information is also explained by the deterioration of proprioceptive inputs with age (Deveze et al. 2014; Iwasaki and Yamasoba 2014; Clemens et al. 2011; Alberts et al. 2016). The biological mechanisms at play are multiple. Recently, Karmali et al. $(2017,2018)$ explained changes in gaze stabilization strategies with age (Dimitri et al. 2001) as an adaptation to the gradual disappearance of hair cells from semicircular canals. Similarly, adaptations of postural control would be initiated by the loss of utricular and saccular hair cells. A priori, cell loss in the five vestibular sensors would progress at the same rate (Gleeson and Felix 1987; Matheson et al. 1999).

\section{Style and learning}

When a new task in an unstable environment is learned, the CNS must find a motor strategy that reduces the risk of errors, while remaining energy efficient (Ter Horst et al. 2015). This learning is accompanied by a reweighting in the processing of sensory input. For example, in the case of a unipedal learning task on an unstable surface, van Dieën et al. (2015) showed that the initial presence of postural oscillations, with training, became associated first with an increase in the weighting of visual information, and then with a decrease in the weighting of proprioceptive information. As another example, tightrope walkers make extensive use of rapid head and trunk movements to maintain balance and a significant weighting of proprioception of neck and lumbosacral regions (Honegger et al. 2013). The reader interested in the reweighting of sensory information in the athlete can also refer to several studies on the subject (Kioumourtzoglou et al. 1998; Paull and Glencross 1997; Bringoux et al. 2000, Vuillerme et al. 2001; Hamill et al. 2012; Busquets et al. 2018; Mo and Chow 2018). The conclusion of Thalassinos et al. (2018) is interesting to conclude this point: each sport would favor a particular weighting in the use of sensory information. Tightrope walkers and dancers favor proprioceptive afferences, footballers favor visual afferences etc. Notice that studies in the field of sports science have described differences between professionals and novices, differences between different kinds of sport, and also differences among experts of the same sport (e.g., Nasu et al. 2014). Finally, Smyth et al. (2019) have shown that the reduction in cortisol reactivity to psychosocial stress in healthy women is linked to a greater visual dependence in postural control, which opens up a vast field of study that remains to be explored on the links between affect, stress and sensory weighting. 


\section{Mechanistic bases}

The origin of perceptual-motor styles is still as mysterious as the origin of painting styles of Monet or Renoir. In line of principle, inter-individual differences in sensorimotor neural circuitries and their coupling with peripheral mechanics may be shaped by genetics, development, motor exploration, experience, training and/or pathology. Some progress has been made toward identifying elements that may contribute to creating inter-individual differences in sensorimotor performance, such as a different conformity to optimal training (Bianchi et al 1998), different adherence to distinct developmental stages (Maselli et al. 2019), learning strategy (Pacheco and Newell 2018) plus memory during task practice (Ganesh et al. 2010; Loeb 2012), and gene-mediated factors (Williams and Gross 1980). In particular, significant genetic effects on both performance levels and rates of improvement have been suggested by comparing monozygotic with dizygotic twins in a variety of tasks, including manual tracking, tapping speed, reaching, and balance, with heritability values ranging between about 20 and $50 \%$ as a function of the task (Williams and Gross 1980; Fox et al. 1996; Missitzi et al. 2013; Zempo et al. 2017; Christova et al. 2020). However, the relative importance of genetic variation in skill development remains controversial (Yarrow et al. 2009).

Irrespective of the extent to which individual styles depend on genetic factors, one may ask the question of the developmental stage at which sensorimotor patterns become unique (Gandevia et al. 2019). Healthy human newborns exhibit considerable variability in their spontaneous movements, such as leg kicking or arm flailing (Sylos-Labini et al. 2020). However, we still do not know how distinct these motor patterns are, whether they exhibit individual features, how they develop over time and become truly idiosyncratic of each person.

The number of studies specifically addressing the mechanistic underpinnings of style is still limited. One approach consists of investigating the individual neural strategies involved in the control of a motor task. In a recent study (Avrillon et al. 2020), high-density surface electromyography recordings were decomposed into motor unit action potentials for a task involving submaximal isometric knee extensions. The results showed that the neural strategies to control two knee extensor muscles (vastus lateralis and vastus medialis) varied widely across individuals, the individual strategies being consistent across sessions interspaced by 20 months. Specifically, the distribution of the strength of neural drive between the vastus lateralis and vastus medialis, as well as the proportion of neural drive shared within and between these muscles varied across participants. The coordination of vastus lateralis and vastus medialis is important for the regulation of the internal stress forces of the knee joint (Alessandro et al. 2020). Accordingly, a large common drive between these muscles observed in the majority of the participants of the study by Avrillon et al. (2020) might represent an efficient strategy to prevent knee injury. By contrast, the lower common drive observed in a minority of participants might be associated with a higher risk of developing kneerelated injuries.

The neural basis of the individual differences in locomotion (e.g., Bianchi et al. 1998; Hug et al. 2019; Mantilla et al. 2020) is still unknown. Individual differences may arise from, among other factors, the almost unlimited potential combinations of neural activity due to variable, dynamic reconfiguration of the circuits (Marder 2011) and their redundant organization (Hultborn 2001). Thus, a recent study showed a striking redundancy in the spinal locomotor networks of a mouse model (Pham et al. 2020). Using differential labelling of spinal interneurons, the study showed that between two 30-min bouts of stepping, each consisting of thousands of steps, only $20 \%$ of the neurons activated from the first bout of stepping were also activated by the second bout. This finding suggests that variability of neural networks organization may enable the selection of many different combinations of neurons when generating each step cycle.

Other interesting approaches to investigate putative neural substrates of individual perceptual-motor styles involve the description of individual patterns of brain activity in humans. By correlating kinematics and fMRI responses, it has been shown that kinematic variability and parietal and prefrontal cortical variability are stable individual traits, consistent across movements to different targets when performed by either the right or left arm (Haar et al. 2017). The same study also showed that subjects with larger neural variability in the inferior parietal lobule have larger movement-extent variability. Another fMRI study scanned a reinforcement learning task in which participants stopped a rotating clock hand to win points (Badre and Frank 2012). The results showed that the pattern of activity in rostrolateral prefrontal cortex distinguished individuals who rely on relative uncertainty for their exploratory decisions versus those who do not. Another recent study (Xue et al. 2021) used functional connectivity MRI to examine the cerebellum of two intensively-sampled individuals (each scanned 31 times) and found idiosyncratic spatial details between these subjects.

Hilt et al. (2020) addressed the issue of how individual motor styles are dealt with during action observation. They asked participants to first perform and then observe a wholebody reaching action that could be performed according to several different styles, generally spread within a continuum between two extreme strategies (see above, Hilt et al. 2016). 
Then, they measured the corticospinal excitability of the participants by applying transcranial magnetic stimulation on the motor cortex while the participants observed an actor achieving the same goal by using the two extreme strategies of action. They found that the individual corticospinal excitability was an inverse function of the distance between the observer's style and the actor's style, in other words, the corticospinal excitability was greater the closer were the observer's style and the actor's style.

\section{Perspectives}

As this review has attempted to broadly summarize, the perceptual-motor style may vary from one individual to another, from one task to another, from one pathology to another, as sensorimotor transformations show considerable adaptability and plasticity. While the behavioral evidence for individual styles is already quite significant, much work remains to be done to understand the neural and mechanical substrates of the inter-individual differences in sensorimotor performance.

It should also be stressed that the fact that the perceptualmotor style may change during intensive physical activity or during the course of a disease does not in any way guarantee that it is for the benefit of the athlete or the patient. Again, functional or post-injury plasticity, while well established, has not been proven to be effective or harmful when it occurs spontaneously. On the other hand, numerous studies also show that the perceptual-motor style can evolve with proactive learning. Whether we talk about training in sports or re-education in patients, the issues are similar.

In this context, we plead for training, learning and rehabilitation to be the subject of longitudinal studies so that they can be optimized for the benefit of athletes and patients. The identification of perceptuo-motor styles via the quantification of reliable markers of individual behavior would help considerably to develop personalized treatments. This goal seemed almost unattainable until recently, because it involves the detailed quantification of a wide range of critical performance parameters in normal and pathological human behavior in realistic settings. Recent progress with intensive computational methods now makes the goal within our reach.

Finally, it must be stressed that the study of sensorimotor transformations and the perceptual-motor style has important implications for rehabilitation practice. Rehabilitation, for purely economic reasons, is still largely under-dosed. With the ageing of the population and the problem of maintaining autonomy, this policy is no longer tenable (Vidal et al. 2020). Personalized approaches along with precision diagnostics will pave the way to many improved treatments.
Author contributions P-PV and FL contributed equally towards the conception and writing of the article.

Funding Open access funding provided by Università degli Studi di Roma Tor Vergata within the CRUI-CARE Agreement. This work was supported by the Italian Ministry of Health (Ricerca corrente, IRCCS Fondazione Santa Lucia), Italian Space Agency (Grants I/006/06/0 and ASI-MARS-PRE DC-VUM-2017-006), and Italian University Ministry (PRIN grant 2017CBF8NJ_005).

\section{Compliance with ethical standards}

Conflict of interest The authors declare that they have no conflict of interest.

Open Access This article is licensed under a Creative Commons Attribution 4.0 International License, which permits use, sharing, adaptation, distribution and reproduction in any medium or format, as long as you give appropriate credit to the original author(s) and the source, provide a link to the Creative Commons licence, and indicate if changes were made. The images or other third party material in this article are included in the article's Creative Commons licence, unless indicated otherwise in a credit line to the material. If material is not included in the article's Creative Commons licence and your intended use is not permitted by statutory regulation or exceeds the permitted use, you will need to obtain permission directly from the copyright holder. To view a copy of this licence, visit http://creativecommons.org/licenses/by/4.0/.

\section{References}

Abernethy B, Zawi K, Jackson RC (2008) Expertise and attunement to kinematic constraints. Perception 37:931-948. https://doi. org/10.1068/p5340

Aglioti SM, Cesari P, Romani M, Urgesi C (2008) Action anticipation and motor resonance in elite basketball players. Nat Neurosci 11:1109-1116. https://doi.org/10.1038/nn.2182

Alberts BBGT, Selen LPJ, Bertolini G, Straumann D, Medendorp WP, Tarnutzer AA (2016) Dissociating vestibular and somatosensory contributions to spatial orientation. J Neurophysiol 116:3-40

Alberts BBGT, Selen LPJ, Verhagen WIM, Pennings RJE, Medendorp WP (2018) Bayesian quantification of sensory reweighting in a familial bilateral vestibular disorder (DFNA9). J Neurophysiol 119:1209-1221

Alberts BBGT, Selen LPJ, Medendorp WP (2019) Age-related reweighting of visual and vestibular cues for vertical perception. J Neurophysiol 121(4):1279-1288

Alessandro C, Barroso FO, Prashara A, Tentler DP, Yeh HY, Tresch MC (2020) Coordination amongst quadriceps muscles suggests neural regulation of internal joint stresses, not simplification of task performance. Proc Natl Acad Sci USA 17(14):8135-8142

Allison LK, Kiemel T, Jeka JJ (2006) Multisensory reweighting of vision and touch is intact in healthy and fall-prone older adults. Exp Brain Res 175(2):342-352. https://doi.org/10.1007/s0022 1-006-0559-7 (PubMed: 16858599)

Altman AR, Reisman DS, Higginson JS, Davis IS (2012) Kinematic comparison of split-belt and single-belt treadmill walking and the effects of accommodation. Gait Posture 35(2):287-291. https:// doi.org/10.1016/j.gaitpost.2011.09.101

Angelaki DE, Cullen KE (2008) Vestibular system: the many facets of a multimodal sense. Annu Rev Neurosci 31:125-150 
Angelaki DE, Gu Y, DeAngelis GC (2009) Multisensory integration: psychophysics, neurophysiology, and computation. Curr Opin Neurobiol 19(4):452-458

Anson E, Jeka J (2016) Perspectives on aging vestibular function. Front Neurol 6(6):269. https://doi.org/10.3389/fneur.2015.00269

Anzulewicz A, Sobota K, Delafield-Butt J (2016) Toward the autism motor signature. Sci Rep 6:31107

Assländer L (2016) Peterka RJ Sensory reweighting dynamics following removal and addition of visual and proprioceptive cues. J Neurophysiol 116(2):272-285. https://doi.org/10.1152/jn.01145 2015 (Epub 2016 Apr 13)

Assländer L, Peterka RJ (2014) Sensory reweighting dynamics in human postural control. J Neurophysiol 111(9):1852-1864. https ://doi.org/10.1152/jn.00669.2013 (Epub 2014 Feb 5)

Avrillon S, Guilhem G, Barthelemy A, Hug F (2018) Coordination of hamstrings is individual specific and is related to motor performance. J Appl Physiol 125(4):1069-1079

Avrillon S, Del Vecchio A, Farina D, Pons JL, Vogel C, Umehara J, Hug F (2020) Individual differences in the neural strategies to control the lateral and medial head of the quadriceps during a mechanically constrained task. J Appl. https://doi.org/10.1152/ japplphysiol.00653.2020

Ayoubi F, Launay CP, Annweiler C, Beauchet O (2015) Fear of falling and gait variability in older adults: a systematic review and meta-analysis. J Am Med Dir Assoc 16(1):14-19. https://doi. org/10.1016/j.jamda.2014.06.020

Badre D, Frank MJ (2012) Mechanisms of hierarchical reinforcement learning in cortico-striatal circuits 2: evidence from fMRI. Cereb Cortex 22(3):527-536. https://doi.org/10.1093/cercor/bhr117

Bair WN, Kiemel T, Jeka JJ, Clark JE (2007) Development of multisensory reweighting for posture control in children. Exp Brain Res 183(4):435-446

Barclay C, Cutting J, Kozlowski L (1978) Temporal and spatial factors in gait perception that influence gender recognition. Percept Psychophys 23:145-152

Barela JA, Jeka JJ, Clark JE (1999) The use of somatosensory information during the acquisition of independent upright stance. Infant Behav Dev 22(1):87-102

Barela JA, Godoi D, Freitas Júnior PB, Polastri PF (2000) Visual information and body sway coupling in infants during sitting acquisition. Infant Behav Dev 23:285-297

Barela JA, Jeka JJ, Clark JE (2003) Postural control in children: coupling to dynamic somatosensory information. Exp Brain Res 150:434-442

Barela AM, Barela JA, Rinaldi NM, de Toledo DR (2009) Influence of imposed optic flow characteristics and intention on postural responses. Mot Control 13(2):119-129 (PubMed: 19454775)

Bargary G, Bosten JM, Goodbourn PT, Lawrance-Owen AJ, Hogg RE, Mollon JD (2017) Individual differences in human eye movements: an oculomotor signature? Vis Res 141:157-169

Bertenthal BI, Boker SM, Xu M (2000) Analysis of the perceptionaction cycle for visually induced postural sway in 9-month-old sitting infants. Infant Behav Dev 23:299-315

Bianchi L, Angelini D, Lacquaniti F (1998) Individual characteristics of human walking mechanics. Pflügers Archiv 436(3):343-356

Blake R, Shiffrar M (2007) Perception of human motion. Annu Rev Psychol 58:47-73

Block HJ, Bastian AJ (2011) Sensory weighting and realignment: independent compensatory processes. J Neurophysiol 106(1):59-70

Blouin J, Teasdale N, Mouchnino L (2007) Vestibular signal processing in a subject with somatosensory deafferentation: the case of sitting posture. BMC Neurol 29(7):25

Bonan IV, Leblong E, Leplaideur S, Laviolle B, Tassel Ponche S, Yelnik AP (2016) The effect of optokinetic and galvanic vestibular stimulations in reducing post-stroke postural asymmetry. Clin
Neurophysiol 127(1):842-847. https://doi.org/10.1016/j.clinp h.2015.03.026

Bonan IV, Colle FM, Guichard JP, Vicaut E, Eisenfisz M, Tran Ba Huy P, Yelnik AP (2004) Reliance on visual information after stroke. Part I: Balance on dynamic posturography. Arch Phys Med Rehabil 85(2):268-273

Bonan IV, Derighetti F, Gellez-Leman MC, Bradaï N, Yelnik A (2006) Visual dependence after recent stroke. Ann Readapt Med Phys 49(4):166-171

Bonan IV, Marquer A, Eskiizmirliler S, Yelnik AP, Vidal PP (2013) Sensory reweighting in controls and stroke patients. Clin Neurophysiol 124(4):713-722. https://doi.org/10.1016/j.clinp h.2012.09.019 (Epub 22 Oct 2012)

Bonan IV, Gaillard F, Ponche ST, Marquer A, Vidal PP, Yelnik AP (2015) Early post-stroke period: a privileged time for sensory re-weighting? J Rehabil Med 47(6):516-522

Borghese NA, Bianchi L, Lacquaniti F (1996) Kinematic determinants of human locomotion. J Physiol (Lond) 494:863-879

Boyd J, Little J (2005) Biometric gait recognition. In: Advanced studies in biometrics. LNCS, vol 3161. Springer, Heidelberg, pp 19-42

Bringoux L, Marin L, Nougier V, Barraud PA, Raphel C (2000) Effects of gymnastics expertise on the perception of body orientation in the pitch dimension. J Vestib Res 10(6):251-8

Bronstein AM (1999) The interaction of otolith and proprioceptive information in the perception of verticality. The effects of labyrinthine and CNS disease. Ann N Y Acad Sci 871:324-333

Bronstein AM, Yardley L, Moore AP, Cleeves L (1996) Visually and posturally mediated tilt illusion in Parkinson's disease and in labyrinthine defective subjects. Neurology 47(3):651-656. https ://doi.org/10.1212/wnl.47.3.651

Buckley E, Mazzà C, McNeill A (2018) A systematic review of the gait characteristics associated with Cerebellar Ataxia. Gait Posture 60:154-163. https://doi.org/10.1016/j.gaitpost.2017.11.024

Bunday KL, Bronstein AM (2009) Locomotor adaptation and aftereffects in patients with reduced somatosensory input due to peripheral neuropathy. J Neurophysiol 102(6):3119-3128. https://doi. org/10.1152/jn.00304.2009

Busquets A, Aranda-Garcia S, Ferrer-Uris B, Marina M, AnguloBarroso R (2018) Age and gymnastic experience effects on sensory reweighting processes during quiet stand. Gait Posture 63:177-183

Butterworth G, Hicks L (1977) Visual proprioception and postural stability in infancy: a developmental study. Perception 6:256-262

Cakirpaloglu P, Radil T (1992) Perceptual-motor coordination and style in healthy boys and those with minimal brain dysfunction. Percept Mot Skills 75(2):448-450

Calvo-Merino B, Glaser DE, Grèzes J, Passingham RE, Haggard P (2005) Action observation and acquired motor skills: an FMRI study with expert dancers. Cereb Cortex 15(8):1243-1249. https ://doi.org/10.1093/cercor/bhi007

Carpenter MG, Allum JH, Honegger F (2001) Vestibular influences on human postural control in combinations of pitch and roll planes reveal differences in spatiotemporal processing. Exp Brain Res 140(1):95-111

Carver S, Kiemel T, van der Kooij H, Jeka JJ (2005) Comparing internal models of the dynamics of the visual environment. Biol Cybern 92(3):147-163

Carver S, Kiemel T, Jeka JJ (2006) Modeling the dynamics of sensory reweighting. Biol Cybern 95(2):123-134

Catavitello G, Ivanenko Y, Lacquaniti F (2018) A kinematic synergy for terrestrial locomotion shared by mammals and birds. Elife 7:e38190

Cenciarini M, Peterka RJ (2006) Stimulus-dependent changes in the vestibular contribution to human postural control. J Neurophysiol 95(5):2733-2750 
Cesqui B, d'Avella A, Portone A, Lacquaniti F (2012) Catching a ball at the right time and place: individual factors matter. PLoS ONE 7(2):e31770. https://doi.org/10.1371/journal.pone.0031770

Chaisanguanthum KS, Shen HH, Sabes PN (2014) Motor variability arises from a slow random walk in neural state. J Neurosci 34(36): 12071-12080

Chan JS, Yan JH (2018) Age-related changes in field dependence-independence and implications for geriatric rehabilitation: a review. Percept Mot Skills 125(2):234-250

Cheung BS, Howard IP, Nedzelski JM, Landolt JP (1989) Circular vection about earth-horizontal axes in bilateral labyrinthinedefective subjects. Acta Otolaryngol 108(5-6):336-344

Cheung VC, Zheng XC, Cheung RT, Chan RH (2020) Modulating the structure of motor variability for skill learning through specific muscle synergies in elderlies and young adults. IEEE Open J Eng Med Biol 1:33-40

Christova P, Joseph J, Georgopoulos A (2020) Behavioral-genetic associations in the human connectome project. Exp Brain Res 238:2445-2456

Clemens IA, De Vrijer M, Selen LP, Van Gisbergen JA, Medendorp WP (2011) Multisensory processing in spatial orientation: an inverse probabilistic approach. J Neurosci 31(14):5365-5377. https://doi.org/10.1523/JNEUROSCI.6472-10.2011

Corriveau H, Hébert R, Raîche M, Prince F (2004) Evaluation of postural stability in the elderly with stroke. Arch Phys Med Rehabil 85(7):1095-1101

Creath R, Kiemel T, Horak F, Jeka JJ (2002) Limited control strategies with the loss of vestibular function. Exp Brain Res 145(3):323-333

Curthoys IS (2000) Vestibular compensation and substitution. Curr Opin Neurol 13:27-30

Cutting JE, Kozlowski LT (1977) Recognizing friends by their walk: gait perception without familiarity cues. Bull Psychon Soc 9:353-356

Cyr JP, Anctil N, Simoneau M (2019) Balance control mechanisms do not benefit from successive stimulation of different sensory systems. PLoS ONE 14(12):e0226216

Daffertshofer A, Lamoth CJ, Meijer OG, Beek PJ (2004) PCA in studying coordination and variability: a tutorial. Clin Biomech 19(4):415-428

Dakin CJ, Kumar P, Forbes PA, Peters A, Day BL (2020) Variance based weighting of multisensory head rotation signals for verticality perception. PLoS One 15(1):e0227040. https://doi. org/10.1371/journal.pone. 0227040

Dasenbrock L, Heinks A, Schwenk M, Bauer JM (2016) Technology-based measurements for screening, monitoring and preventing frailty. Z Gerontol Geriatr 49(7):581-595. https://doi. org/10.1007/s00391-016-1129-7

Day BL, Cole J (2002) Vestibular-evoked postural responses in the absence of somatosensory information. Brain $125(\mathrm{Pt}$ 9):2081-2088

van Dieën JH, van Leeuwen M, Faber GS (2015) Learning to balance on one leg: motor strategy and sensory weighting. J Neurophysiol 114(5):2967-2982

de Haart M, Geurts AC, Huidekoper SC, Fasotti L, van Limbeek J (2004) Recovery of standing balance in postacute stroke patients: a rehabilitation cohort study. Arch Phys Med Rehabil 85(6):886-895

Delorme A, Frigon JY, Lagacé C (1989) Infant's reactions to visual movement of the environment. Perception 18(5):667-673

Deveze A, Bernard-Demanze L, Xavier F, Lavieille JP, Elziere M (2014) Vestibular compensation and vestibular rehabilitation. Current concepts and new trends. Neurophysiol Clin 44(1):4957. https://doi.org/10.1016/j.neucli.2013.10.138
Dimitri PS, Wall C 3rd, Rauch SD (2001) Multivariate vestibular testing: thresholds for bilateral Ménière's disease and aminoglycoside ototoxicity. J Vestib Res 11(6):391-404

Dingwell JB, Cusumano JP (2015) Identifying stride-to-stride control strategies in human treadmill walking. PLoS One 10(4):e0124879. https://doi.org/10.1371/journal.pone.0124879

Dingwell JB, Salinas MM, Cusumano JP (2017) Increased gait variability may not imply impaired stride-tostride control of walking in healthy older adults. Gait Posture 55:131-137. https://doi. org/10.1016/j.gaitpost.2017.03.018

Dhawale AK, Smith MA, Ölveczky BP (2017) The role of variability in motor learning. Annu Rev Neurosci 40:479-498

Di Fabio RP, Badke MB (1991) Stance duration under sensory conflict conditions in patients with hemiplegia. Arch Phys Med Rehabil 72(5):292-295

Ettinger U, Kumari V, Crawford TJ, Davis RE, Sharma T, Corr PJ (2003) Reliability of smooth pursuit, fixation, and saccadic eye movements. Psychophysiology 40(4):620-628

Evans C, Richardson JT, Waring M (2013) Field independence: reviewing the evidence. Br J Educ Psychol 83(2):210-224

Faisal AA, Selen LP, Wolpert DM (2008) Noise in the nervous system. Nat Rev Neurosci 9(4):292-303

Faralli M, Longari F, Ricci G, Ibba MC, Frenguelli A (2009) Influence of extero- and proprioceptive afferents of the plantar surface in determining subjective visual vertical in patients with unilateral vestibular dysfunction. Acta Otorhinolaryngol Ital 29(5):245-250

Fernie E (1995) Art history and its methods: a critical anthology. Phaidon, London, p 361

Figueiredo J, Santos CP, Moreno JC (2018) Automatic recognition of gait patterns in human motor disorders using machine learning: A review. Med Eng Phys 53:1-12. https://doi.org/10.1016/j. medengphy.2017.12.006

Fitzpatrick RC, Taylor JL, McCloskey DI (1992) Ankle stiffness of standing humans in response to imperceptible perturbation: reflex and task-dependent components. J Physiol 454:533-547

Forssberg H, Nashner LM (1982) Ontogenetic development of postural control in man: adaptation to altered support and visual conditions during stance. J Neurosci 2(5):545-552 (PubMed: 7077364)

Fox P, Hershberger S, Bouchard T (1996) Genetic and environmental contributions to the acquisition of a motor skill. Nature 28:356-358

Gan G, Ma C, Wu J (2007) Data clustering: theory, algorithms, and applications. ASA-SIAM Series on Statistics and Applied Probability. SIAM, Philadelphia

Gandevia SC, Muceli S, Héroux M (2019) Signing up to motor signatures: a unique link to action. J Appl Physiol 127(4):1163-1164

Ganesh G, Haruno M, Kawato M, Burdet E (2010) Motor memory and local minimization of error and effort, not global optimization, determine motor behavior. J Neurophysiol 104(1):382-390

Geurts AC, de Haart M, van Nes IJ, Duysens J (2005) A review of standing balance recovery from stroke. Gait Posture 22(3):267281. https://doi.org/10.1016/j.gaitpost.2004.10.002

Gibson JJ (1952) The relation between visual and postural determinants of the phenomenal vertical. Psychol Rev 59:370-375

Giese MA, Poggio T (2003) Neural mechanisms for the recognition of biological movements. Nat Rev Neurosci 4(3):179-192

Gleeson M, Felix H (1987) A comparative study of the effect of age on the human cochlear and vestibular neuroepithelia. Acta Otolaryngol Suppl 436:103-109

Godoi D, Barela JA (2008) Body sway and sensory motor coupling adaptation in children: effects of distance manipulation. Dev Psychobiol 50(1):77-87. https://doi.org/10.1002/dev.20272 
Golenia L, Schoemaker MM, Mouton LJ, Bongers RM (2014) Individual differences in learning a novel discrete motor task. PLoS ONE 9(11):e112806

Gombrich EH (1998) Style. In: Preziosi D (ed) The art of art history: a critical anthology. Oxford University Press, New York, p 150

Goodworth AD, Peterka RJ (2012) Sensorimotor integration for multisegmental frontal plane balance control in humans. J Neurophysiol 107(1):12-28

Green AM, Angelaki DE (2010) Multisensory integration: resolving sensory ambiguities to build novel representations. Curr Opin Neurobiol 20(3):353-360

Guerraz M, Bronstein AM (2008) Ocular versus extraocular control of posture and equilibrium. Neurophysiol Clin 38(6):391-398

Guerraz M, Yardley L, Bertholon P, Pollak L, Rudge P, Gresty MA, Bronstein AM (2001) Visual vertigo: symptom assessment, spatial orientation and postural control. Brain 485(124):1646-1656

Haar S, Donchin O, Dinstein I (2017) Individual movement variability magnitudes are explained by cortical neural variability. J Neurosci 37:9076-9085

Han J, Bhanu B (2005) Individual recognition using gait energy image. IEEE Trans Pattern Anal Mach Intell 28(2):316-322

Hamill J, Palmer C, Van Emmerik REA (2012) Coordinative variability and overuse injury. Sports Med Arthrosc Rehabil Ther Technol 4(1):45. https://doi.org/10.1186/1758-2555-4-45

Hardwick RM, Forrence AD, Krakauer JW, Haith AM (2019) Timedependent competition between goal-directed and habitual response preparation. Nat Hum Behav 3:1252-1262

Harris CM, Wolpert DM (1998) Signal-dependent noise determines motor planning. Nature 394:780-784

Harris LR, Sakurai K, Beaudot WHA (2017) Tactile flow overrides other cues to self motion. Sci Rep 7(1):1059

Herssens N, McCrum C (2019) Stimulating balance: recent advances in vestibular stimulation for balance and gait. J Neurophysiol 122(2):447-450

Herssens N, Verbecque E, Hallemans A, Vereeck L, Van Rompaey V, Saeys W (2018) Do spatiotemporal parameters and gait variability differ across the lifespan of healthy adults? A systematic review. Gait Posture 64:181-190. https://doi.org/10.1016/j.gaitp ost.2018.06.012

Higgins CI, Campos JJ, Kermoiann R (1996) Effect of self-produced locomotion on infant postural compensation to optic flow. Dev Psychol 32(5):836-841

Hill H, Pollick FE (2000) Exaggerating temporal differences enhances recognition of individuals from point light displays. Psychol Sci 11(3):223-228

Hilt PM, Berret B, Papaxanthis C, Stapley PJ, Pozzo T (2016) Evidence for subjective values guiding posture and movement coordination in a free-endpoint whole-body reaching task. Sci Rep 6:23868

Hilt PM, Cardellicchio P, Dolfini E, Pozzo T, Fadiga L, D'Ausilio A (2020) Motor recruitment during action observation: effect of interindividual differences in action strategy. Cereb Cortex 30(7):3910-3920

Honegger F, Tielkens RJ, Allum JH (2013) Movement strategies and sensory reweighting in tandem stance: differences between trained tightrope walkers and untrained subjects. Neuroscience 19(254):285-300

Honeine JL, Crisafulli O, Sozzi S, Schieppati M (2015) Processing time of addition or withdrawal of single or combined balance-stabilizing haptic and visual information. J Neurophysiol 114(6):3097-3110

Horak FB, Hlavacka F (2001) Somatosensory loss increases vestibulospinal sensitivity. J Neurophysiol 86(2):575-585

Horst F, Mildner M, Schöllhorn WI (2017) One-year persistence of individual gait patterns identified in a follow-up study?A call for individualized diagnose and therapy. Gait Posture 58:476-480
Horst F, Lapuschkin S, Samek W, Muller KR, Schollhorn WI (2019) Explaining the unique nature of individual gait patterns with deep learning. Sci Rep 9:2391

Hug F, Vogel C, Tucker K, Dorel S, Deschamps T, Le Carpentier É, Lacourpaille L (2019) Individuals have unique muscle activation signatures as revealed during gait and pedaling. J Appl Physiol 127(4):1165-1174

Hultborn H (2001) State-dependent modulation of sensory feedback. J Physiol 533:5-13

Hwang S, Agada P, Kiemel T, Jeka JJ (2014) Dynamic reweighting of three modalities for sensor fusion. PLoS ONE 9(1):e88132

Isableu B, Ohlmann T, Crémieux J, Amblard B (2003) Differential approach to strategies of segmental stabilisation in postural control. Exp Brain Res 150(2):208-221

Issartel J, Marin L, Cadopi M (2007) Unintended interpersonal coordination: can we march to the beat of our own drum?? Neurosci Lett 411(3):174-179

Ivanenko YP, Cappellini G, Solopova IA, Grishin AA, Maclellan MJ, Poppele RE, Lacquaniti F (2013) Plasticity and modular control of locomotor patterns in neurological disorders with motor deficits. Front Comput Neurosci 7:123

Iwasaki S, Yamasoba T (2014) Dizziness and imbalance in the elderly: age-related decline in the vestibular system. Aging Dis 6(1):3847. https://doi.org/10.14336/AD.2014.0128

Jamali M, Mitchell D, Dale A (2014) Neuronal detection thresholds during vestibular compensation: contributions of response variability and sensory substitution. J Neurophysiol 592:1565-1580

Jansiewicz EM et al (2006) Motor signs distinguish children with high functioning autism and Asperger's syndrome from controls. J Autism Dev Disord 36:613-621

Jastorff J, Orban GA (2009) Human functional magnetic resonance imaging reveals separation and integration of shape and motion cues in biological motion processing. J Neurosci 29:7315-7329

Jeka JJ, Oie KS, Kiemel T (2000) Multisensory information for human postural control: Integrating touch and vision. Exp Brain Res 134(1):107-125. https://doi.org/10.1007/s002210000412

Jeka JJ, Allison L, Saffer M, Zhang Y, Carver S et al (2006) Sensory reweighting with translational visual stimuli in young and elderly adults:the role of state-dependent noise. Exp Brain Res 174(3):517-527

Johansson G (1975) Visual motion perception. Sci Am 232(6):76-89

Kabbaligere R, Lee BC, Layne CS (2017) Balancing sensory inputs: sensory reweighting of ankle proprioception and vision during bipedal posture task. Gait Posture 52:244-250

Karmali F, Bermudez Rey MC, Clark TK, Wang W, Merfeld DM (2017) Multivariate analyses of balance test performance, vestibular thresholds, and age. Front Neurol 8:578

Karmali F, Whitman GT, Lewis RF (2018) Bayesian optimal adaptation explains age-related human sensorimotor changes. J Neurophysiol 119:509-520

Kaye DH (2009) Probability, individualization, and uniqueness in forensic science evidence-listening to the academies. Brook L Rev 75:1163-1185

Kim J, Curthoys IS (2004) Responses of primary vestibular neurons to galvanic vestibular stimulation (GVS) in the anaesthetised guinea pig. Brain Res Bull 64:265-271

Kikkert LHJ, Vuillerme N, van Campen JP, Hortobágyi T, Lamoth CJ (2016) Walking ability to predict future cognitive decline in old adults: A scoping review. Ageing Res Rev 27:1-14. https://doi. org/10.1016/j.arr.2016.02.001

Kioumourtzoglou E, Kourtessis T, Michalopoulou M, Derri V (1998) Differences in several perceptual abilities between experts and novices in basketball, volleyball and water polo. Percept Mot Skills 86:899-912

Kluzik J, Horak FB, Peterka RJ (2007) Postural after-effects of stepping on an inclined surface. Neurosci Lett 413(2):93-98 
Kozhevnikov M (2007) Cognitive styles in the context of modern psychology: toward an integrated framework of cognitive style. Psychol Bull 133(3):464-481

König N, Taylor WR, Baumann CR, Wenderoth N, Singh NB (2016) Revealing the quality of movement: A meta-analysis review to quantify the thresholds to pathological variability during standing and walking. Neurosci Biobehav Rev 68:111-119. https:// doi.org/10.1016/j.neubiorev.2016.03.035

Kraan CM, Tan AHJ, Cornish KM (2017) The developmental dynamics of gait maturation with a focus on spatiotemporal measures. Gait Posture 51:208-217. https://doi.org/10.1016/j.gaitp ost.2016.10.021

La Scaleia B, Zago M, Lacquaniti F (2015) Hand interception of occluded motion in humans: a test of model-based vs on-line control. J Neurophysiol 114(3):1577-1592

Lacour M, Helmchen C, Vidal PP (2016) Vestibular compensation: the neuro-otologist's best friend. J Neurol 263(Suppl 1):S54-S64

Lacquaniti F (1997) Frames of reference in sensorimotor coordination. Handb Neuropsychol 11:27-63

Lacquaniti F, Maioli C (1994) Coordinate transformations in the control of cat posture. J Neurophysiol 72(4):1496-1515

Lacquaniti F, Terzuolo C, Viviani P (1983) The law relating the kinematic and figural aspects of drawing movements. Acta Physiol (Oxf) 54(1-3):115-130

Lacquaniti F, Grasso R, Zago M (1999) Motor patterns in walking. News Physiol Sci 14:168-174

Lacquaniti F, Bosco G, Gravano S, Indovina I, La Scaleia B, Maffei V, Zago M (2014) Multisensory integration and internal models for sensing gravity effects in primates. Biomed Res Int 2014:615854. https://doi.org/10.1155/2014/615854

Lee DN, Aronson E (1974) Visual proprioceptive control of standing in human infants. Percept Psychophys 15(3):529-532

Lindberg S, Siesjö P, Magnusson M (2008) PREHAB vs. REHABpresurgical treatment in vestibular schwannoma surgery enhances recovery of postural control better than postoperative rehabilitation: retrospective case series. J Vestib Re 27(5-6):313-325. https://doi.org/10.3233/VES-170626

Lisberger SG, Medina JF (2015) How and why neural and motor variation are related. Curr Opin Neurobiol 33:110-116

Lishman JR, Lee DN (1973) The autonomy of visual kinaesthesis. Perception 2:287-294

Loeb GE (2012) Optimal isn't good enough. Biol Cybern 106(11-12):757-765

Logan D, Kiemel T (2014) Jeka JJ (2014) Asymmetric sensory reweighting in human upright stance. PLoS ONE 9(6):e100418. https://doi.org/10.1371/journal.pone.0100418 (eCollection 2014)

Lopez C, Lacour M, Ahmadi A, Magnan J, Borel L (2007) Changes of visual vertical perception: a long-term sign of unilateral and bilateral vestibular loss. Neuropsychologia 45:2025-2037

Loula F, Prasad S, Harber K, Shiffrar M (2005) Recognizing people from their movement. J Exp Psychol Hum Percept Perform 31(1):210-220

Maffei V, Indovina I, Macaluso E, Ivanenko YP, Orban GA, Lacquaniti $\mathrm{F}$ (2015) Visual gravity cues in the interpretation of biological movements: neural correlates in humans. NeuroImage 104:221-230

Maffei V, Indovina I, Mazzarella E, Giusti MA, Macaluso E, Lacquaniti F, Viviani P (2020) Sensitivity of occipito-temporal cortex, premotor and Broca's areas to visible speech gestures in a familiar language. PLoS ONE 15(6):e0234695

Magnusson M, Padoan S (1991) Delayed onset of ototoxic effects of gentamicin in treatment of Menière's disease. Rationale for extremely low dose therapy. Acta Otolaryngol 111(4):671-676

Mahboobin A, Loughlin PJ, Redfern MS, Sparto PJ (2005) Sensory re-weighting in human postural control during moving-scene perturbations. Exp Brain Res 167(2):260-267 (Epub 15 Nov 2005)

Maki BE, Holliday PJ, Topper AK (1994) A prospective study of postural balance and risk of falling in an ambulatory and independent elderly population. J Gerontol 49(2):M72-84

Mann DL, Abernethy B, Farrow D (2010) Action specificity increases anticipatory performance and the expert advantage in natural interceptive tasks. Acta Psychol (Amst) 135:17-23. https://doi. org/10.1016/j.actpsy.2010.04.006

Mantilla J, Wang D, Bargiotas I, Wang J, Cao J, Oudre L, Vidal PP (2020) Motor style at rest and during locomotion in human. J Neurophysiol. https://doi.org/10.1152/jn.00019.2019

Marder E (2011) Variability, compensation, and modulation in neurons and circuits. Proc Natl Acad Sci 108(Supplement 3): $15542-15548$

Marsden JF, Playford DE, Day BL (2005) The vestibular control of balance after stroke. J Neurol Neurosurg Psychiatry 76(5):670-678

Maselli A, Dhawan A, Cesqui B, Russo M, Lacquaniti F, d'Avella A (2017) Where are you throwing the ball? I better watch your body, not just your arm! Front Hum Neurosci 11:505

Maselli A, Dhawan A, Russo M, Cesqui B, Lacquaniti F, d'Avella A (2019) A whole body characterization of individual strategies, gender differences, and common styles in overarm throwing. J Neurophysiol 122(6):2486-2503

Massion J (1994) Postural control system. Curr Opin Neurobiol 4(6):877-887

Mawase F, Bar-Haim S, Joubran K, Rubin L, Karniel A, Shmuelof L (2016) Increased adaptation rates and reduction in trial-by-trial variability in subjects with cerebral palsy following a multi-session locomotor adaptation training. Front Hum Neurosci 10:203. https://doi.org/10.3389/fnhum.2016.00203

Matjacić Z, Voigt M, Popović D, Sinkjaer T (2001) Functional postural responses after perturbations in multiple directions in a standing man: a principle of decoupled control. J Biomech 34(2):187-196

Matheson AJ, Darlington CL, Smith PF (1999) Dizziness in the elderly and age-related degeneration of the vestibular system. NZ J Psychol 28(1):10-6

Maurer C, Peterka RJ (2005) A new interpretation of spontaneous sway measures based on a simple model of human postural control. J Neurophysiol 93:189-200

Merfeld DM, Zupan L, Peterka RJ (1999) Humans use internal models to estimate gravity and linear acceleration. Nature 398(6728):615-618

Meso AI, De Vai RL, Mahabeer A, Hills PJ (2020) Evidence of inverted-gravity driven variation in predictive sensorimotor function. Eur J Neurosci. https://doi.org/10.1111/ejn.14926

Metcalfe JS, McDowell K, Chang TY, Chen LC, Jeka JJ et al (2005) Development of somatosensory-motor integration: an eventrelated analysis of infant posture in the first year of independent walking. Dev Psychobiol 46:19-35

Missitzi J, Gentner R, Misitzi A, Geladas N, Politis P, Klissouras V, Classen J (2013) Heritability of motor control and motor learning. Physiol Rep 1(7):e00188

Mo S, Chow DHK (2018) Stride-to-stride variability and complexity between novice and experienced runners during a prolonged run at anaerobic threshold speed. Gait Posture 64:7-11. https://doi. org/10.1016/j.gaitpost.2018.05.021

Möhler F, Marahrens S, Ringhof S, Mikut R, Stein T (2020) Variability of running coordination in experts and novices: A 3D uncontrolled manifold analysis. Eur J Sport Sci 20(9):1187-1196. https ://doi.org/10.1080/17461391.2019.1709561

Moon M, Chang SO, Kim MB (2017) Diverse clinical and laboratory manifestations of bilateral vestibulopathy. Laryngoscope 127(1):E42-E49. https://doi.org/10.1002/lary.25946

Moore IS (2016) Is there an economical running technique? A review of modifiable biomechanical factors affecting running economy. 
Sports Med 46(6):793-807. https://doi.org/10.1007/s4027 9-016-0474-4

Mortaza N, Abu Osman NA, Mehdikhani N (2014) Are the spatiotemporal parameters of gait capable of distinguishing a faller from a non-faller elderly? Eur J Phys Rehabil Med 50(6):677-91

Moya GBL, Siqueira CM, Caffaro RR, Fu C, Tanaka C (2009) Can quiet standing posture predict compensatory postural adjustment? Clinics 64(8):791-796

Müller H, Sternad D (2004) Decomposition of variability in the execution of goal-oriented tasks?Three components of skill improvement. J Exp Psychol Hum Percept Perform 30:212-233

Mueller Ch, Kornilova L, Wiest G, Steinhoff N (1994) Psychophysical studies of visuo-vestibular interaction in microgravity. Acta Astronaut 33:9-13. https://doi.org/10.1016/0094-5765(94)90102 $-3$

Muller S, Abernethy B, Farrow D (2006) How do worldclass cricket batsmen anticipate a bowler's intention? Q J Exp Psychol (Colchester) 59:2162-2186

Nashner LM (1976) Adapting reflexes controlling the human posture. Exp Brain Res 26(1):59-72

Nashner LM, Black FO, Wall C 3rd (1982) Adaptation to altered support and visual conditions during stance: patients with vestibular deficits. J Neurosci 2(5):536-544

Nasu D, Matsuo T, Kadota K (2014) Two types of motor strategy for accurate dart throwing. PLoS ONE 9:e88536

Newell KM, Deutsch KM, Sosnoff JJ, Mayer-Kress G (2006) Variability in motor output as noise: a default and erroneous proposition? In: Davids K, Bennett S, Newell KM (eds) Movement system variability. Human Kinetics, Champaign, IL, pp 3-24

O'Toole AJ, Phillips PJ, Weimer S, Roark DA, Ayyad J, Barwick R, Dunlop J (2011) Recognizing people from dynamic and static faces and bodies: Dissecting identity with a fusion approach. Vision Res 51(1):74-83

Oie KS, Kiemel T, Jeka JJ (2002) Multisensory fusion: simultaneous re-weighting of vision and touch for the control of human posture. Brain Res Cogn Brain Res 14:164-176 (PubMed: 12063140)

Oman CMI, Howard T, Smith A, Beall A, Natapoff J, Zacher, and H. Jenkin (2003) The Neurolab Spacelab Mission: Neuroscience Research. In: Buckey J, Homick J (eds) Space. NASA SP-2003535. NASA Johnson Space Center, Houston

Pacheco MM, Newell KM (2018) Learning a specific, individual and generalizable coordination function: evaluating the variability of practice hypothesis in motor learning. Exp Brain Res 236(12):3307-3318

Palluel E, Aspell JE, Blanke O (2011) Leg muscle vibration modulates bodily self-consciousness: integration of proprioceptive, visual, and tactile signals. J Neurophysiol 105(5):2239-2247

Parietti-Winkler C, Lion A, Frère J, Perrin PP, Beurton R, Gauchard GC (2016) Prediction of balance compensation after vestibular schwannoma surgery. Neurorehabil Neural Repair 30(5):395-401

Pasma JH, Boonstra TA, Campfens SF, Schouten AC, Van der Kooij H (2012) Sensory reweighting of proprioceptive information of the left and right leg during human balance control. J Neurophysiol 108(4):1138-1148

Pataky TC, Mu T, Bosch K, Rosenbaum D, Goulermas JY (2012) Gait recognition: highly unique dynamic plantar pressure patterns among 104 individuals. J R Soc Interface 9:790-800

Paull G, Glencross D (1997) Expert perception and decision making in baseball. Intern J Sport Psychol 28:35-56

McMahon MJA (2003) The possibility of perceptual style. J Aesthet Art Crit 61(3):259-272

Parreira RB, Grecco LAC, Oliveira CS (2017) Postural control in blind individuals: A systematic review. Gait Posture 57:161-167. https ://doi.org/10.1016/j.gaitpost.2017.06.008
Pérennou DA, Leblond C, Amblard B, Micallef JP, Hérisson C, Pélissier JY (2001) Transcutaneous electric nerve stimulation reduces neglect-related postural instability after stroke. Arch Phys Med Rehabil 82(4):440-448. https://doi.org/10.1053/ apmr.2001.21986

Pérennou D (2006) Postural disorders and spatial neglect in stroke patients: a strong association. Restor Neurol Neurosci 24(4-6):319-334

Pérennou D, Bénaïm C, Rouget E, Rousseaux M, Blard JM, Pélissier J (1999) Postural balance following stroke: towards a disadvantage of the right brain-damaged hemisphere. Rev Neurol (Paris) 155(4):281-290

Peterka RJ (2002) Sensorimotor integration in human postural control. J Neurophysiol 88:1097-1118 (PubMed: 12205132)

Peterka RJ, Benolken MS (1995) Role of somatosensory and vestibular cues in attenuating visually induced human postural sway. Exp Brain Res 105:101-110

Peterka RJ, Loughlin PJ (2004) Dynamic regulation of sensorimotor integration in human postural control. J Neurophysiol 91:410-423

Peterson ML, Christou E, Rosengren KS (2006) Children achieve adultlike sensory integration during stance at 12-years-old. Gait Posture 23:455-463

Pham BN, Luo J, Anand H, Kola O, Salcedo P, Nguyen C, Edgerton VR (2020) Redundancy and multifunctionality among spinal locomotor networks. J Neurophysiol 124(5):1469-1479

Pinotti A (2012) Formalism and the history of style. In: Rampley E (ed) Art history and visual studies in Europe. Brill, London, pp 75-90

Plamondon R, Srihari SN (2000) Online and off-line handwriting recognition: a comprehensive survey. IEEE Trans Pattern Anal Mach Intell 22(1):63-84

Polastri PF, Barela JA (2013) Adaptive visual re-weighting in children's postural control. PLoS ONE 8(12):e82215. https://doi. org/10.1371/journal.pone.0082215 (eCollection 2013)

Pollick FE, Paterson HM (2008) Movement style, movement features, and the recognition of affect from human movement. In: Thomas F, Shipley, Jeffrey M (eds) Zacks Understanding events: from perception to action. Oxford Scholarship Online, pp 286-308. https://doi.org/10.1093/acprof:oso/9780195188370.001.0001.

Prilutsky BI, Zatsiorsky VM (2002) Optimization-based models of muscle coordination. Exerc Sport Sci Rev 30(1):32-38

Prioli AC, Freitas Júnior PB, Barela JA (2005) Physical activity and postural control in the elderly: coupling between visual information and body sway. Gerontology 51:145-148

Ravaioli E, Oie KS, Kiemel T, Chiari L, Jeka JJ (2005) Nonlinear postural control in response to visual translation. Exp Brain Res 160:450-459

Regan D, Beverley KI (1979) Binocular and monocular stimuli for motion in depth: changing-disparity and changing-size feed the same motion-in-depth stage. Vis Res 19:1331-1342

Rinaldi NM, Polastri PF, Barela JA (2009) Age-related changes in postural control sensory reweighting. Neurosci Lett 467(3):225-229

Rival C, Ceyte H, Olivier I (2005) Developmental changes of static standing balance in children. Neurosci Lett 376(2):133-136

Rizzolatti G, Craighero L (2004) The mirror-neuron system. Annu Rev Neurosci 27:169-192

Rode G, Klos T, Courtois-Jacquin S, Rossetti Y, Pisella L (2006) Neglect and prism adaptation: a new therapeutic tool for spatial cognition disorders. Restor Neurol Neurosci 24(4-6):347-56

Robbins TW, Costa RM (2017) Habits. Curr Biol 27(22):R1200-R1206

Roberton MA, Halverson LE, Langendorfer S, Williams K (1979) Longitudinal changes in children's overarm throw ball velocities. Res Q 50:256-264. https://doi.org/10.1080/10671315.1979.10615 608

Rosenhall U, Rubin W (1975) Degenerative changes in the human vestibular sensory epithelia. Acta Otolaryngol 79(1-2):67-80 
Saks MJ, Koehler JJ (2008) The individualization fallacy in forensic science evidence. Vand L Rev 61:199-219

Sakurada T, Nakajima T, Morita M, Hirai M, Watanabe E (2017) Improved motor performance in patients with acute stroke using the optimal individual attentional strategy. Sci Rep 7:40592

Sasaki O, Usami S, Gagey PM, Martinerie J, Le Van QM, Arranz P (2002) Role of visual input in nonlinear postural control system. Exp Brain Res 147(1):1-7

Sawers A, Allen JL, Ting LH (2015) Long-term training modifies the modular structure and organization of walking balance control. J Neurophysiol 114(6):3359-3373

Schieppati M, Giordano A, Nardone A (2002) Variability in a dynamic postural task attests ample flexibility in balance control mechanisms. Exp Brain Res 144(2):200-210

Schmuckler MA (1996) Development of visually guided locomotion: barrier crossing by toddlers. Ecol Psychol 8(3):209-236

Schmuckler MA (1997) Children's postural sway in response to lowand high-frequency visual information for oscillation. J Exp Psychol Hum Percept Perform 23(2):528-545 (PubMed: 9104008)

Scholz JP, Schoner G (1999) The uncontrolled manifold concept: identifying control variables for a functional task. Exp Brain Res 126:289-306

Schorer J, Baker J, Fath F, Jaitner T (2007) Identification of interindividual and intraindividual movement patterns in handball players of varying expertise levels. J Mot Behav 39(5):409-421

Schwenk M, Howe C, Saleh A, Mohler J, Grewal G, Armstrong D, Najafi B (2014) Frailty and technology: a systematic review of gait analysis in those with frailty. Gerontology 60(1):79-89. https ://doi.org/10.1159/000354211

Schniepp R, Möhwald K, Wuehr M (2017) Gait ataxia in humans: vestibular and cerebellar control of dynamic stability. J Neurol 264(Suppl 1):87-92. https://doi.org/10.1007/s00415-017-8482-3

Schut IM, Engelhart D, Pasma JH, Aarts RGKM, Schouten AC (2017) Compliant support surfaces affect sensory reweighting during balance control. Gait Posture 53:241-247

Sell TC (2012) An examination, correlation, and comparison of static and dynamic measures of postural stability in healthy, physically active adults. Phys Ther Sport 13(2):80-86

Shenoy KV, Sahani M, Churchland MM (2013) Cortical control of arm movements: a 567 dynamical systems perspective. Annu Rev Neurosci 36:337-359

Shumway-Cook A, Woollacott M (1985) The growth of stability: postural control from a developmental perspective. J Motor Behav 17(2):131-147

Sienko KH, Seidler RD, Carender WJ, Goodworth AD, Whitney SL, Peterka RJ (2018) Potential mechanisms of sensory augmentation systems on human balance control. Front Neurol 12(9):944

Simoneau M, Mercier P, Blouin J, Allard P, Teasdale N (2006) Altered sensory-weighting mechanisms is observed in adolescents with idiopathic scoliosis. BMC Neurosci 19(7):68

Simonsen EB, Alkjær T (2012) The variability problem of normal human walking. Med Eng Phys 34(2):219-224

Słowiński P, Zhai C, Alderisio F, Salesse R, Gueugnon M, Marin L, Bardy BG, di Bernardo M, Tsaneva-Atanasova K (2016) Dynamic similarity promotes interpersonal coordination in joint action. J R Soc Interface 13(116):20151093

Smyrnis N (2008) Metric issues in the study of eye movements in psychiatry. Brain Cogn 68(3):341-358

Smyth N, Flynn M, Rajcani J, Hucklebridge M, Thorn L, Wood C, Golding J, Evans P, Clow A (2019) Attenuated cortisol reactivity to psychosocial stress is associated with greater visual dependency in postural control. Psychoneuroendocrinology 104:185-190

Soechting JF, Flanders M (1992) Moving in three-dimensional space: frames of reference, vectors, and coordinate systems. Annu Rev Neurosci 15(1):167-191
Sparto PJ, Redfern MS, Jasko JG, Casselbrant ML, Mandel EM et al (2006) The influence of dynamic visual cues for postural control in children aged 7-12 years. Exp Brain Res 168:505-516. https ://doi.org/10.1007/s00221-005-0109-8

Sprager S, Juric MB (2015) Inertial sensor-based gait recognition: a review. Sensors 15(9):22089-22127

Srihari SN, Cha SH, Arora H, Lee S (2002) Individuality of handwriting. J Forensic Sci 47(4):1-17

Sternad D (2018) It's not (only) the mean that matters: variability, noise and exploration in skill learning. Curr Opin Behav Sci 20:183-195. https://doi.org/10.1016/j.cobeha.2018.01.004

Stoffregen TA, Schmuckler MA, Gibson EJ (1987) Use of central and peripheral optical flow in stance and locomotion in young walkers. Perception 16:113-119. https://doi.org/10.1068/p1601 13 (PubMed: 3671034)

Strzalkowski ND, Lowrey CR, Perry SD, Williams DR, Wood SJ, Bent LR (2015) Selective weighting of cutaneous receptor feedback and associated balance impairments following short duration space flight. Neurosci Lett 10(592):94-98

Sulway S, Whitney SL (2019) Advances in vestibular rehabilitation. Adv Otorhinolaryngol 82:164-169

Sylos-Labini F, La Scaleia V, Cappellini G, Fabiano A, Picone S, Keshishian ES, Zhvansky DS, Paolillo P, Irina A, D'Avella A, Ivanenko YP, Lacquaniti F (2020) Distinct locomotor precursors in newborn babies. Proc Natl Acad Sci USA 117:9604-9612

Tasseel-Ponche S, Le Liepvre H, Colle F, Andriantsifanetra C, Vidal PP, Bonan IV, Yelnik AP (2017) Rod and frame test and posture under optokinetic stimulation used to explore two complementary aspects of the visual influence in postural control after stroke. Gait Posture 58:171-175

Ter Horst AC, Koppen M, Selen LP (2015) Medendorp WP (2015) Reliability-based weighting of visual and vestibular cues in displacement estimation. PLoS ONE 10(12):e0145015. https ://doi.org/10.1371/journal.pone.0145015 (eCollection 2015)

Thalassinos M, Fotiadis G, Arabatzi F, Isableu B, Hatzitaki V (2018) Sport skill-specific expertise biases sensory integration for spatial referencing and postural control. J Mot Behav 50(4):426-435

Tighilet B, Bordiga P, Cassel R, Chabbert C (2019) Peripheral vestibular plasticity vs central compensation: evidence and questions. J Neurol 266(Suppl 1):27-32

Tilikete C, Rode G, Rossetti Y, Pichon J, Li L, Boisson D (2001) Prism adaptation to rightward optical deviation improves postural imbalance in left-hemiparetic patients. Curr Biol 11(7):524-528. https://doi.org/10.1016/s0960-9822(01)00151-8

Ting LH, McKay JL (2007) Neuromechanics of muscle synergies for posture and movement. Curr Opin Neurobiol 17(6):622-628

Ting LH, Chiel HJ, Trumbower RD, Allen JL, McKay JL, Hackney ME, Kesar TM (2015) Neuromechanical principles underlying movement modularity and their implications for rehabilitation. Neuron 86:38-54. https://doi.org/10.1016/j.neuro n.2015.02.042

Tjernström F, Fransson PA, Kahlon B, Karlberg M, Lindberg S, Siesjö P, Magnusson M (2018) J PREHAB vs. REHAB - presurgical treatment in vestibular schwannoma surgery enhances recovery of postural control better than postoperative rehabilitation: Retrospective case series. Vestib Res 27(5-6):313-325. https://doi. org/10.3233/VES-170626

Todorov E, Jordan MI (2002) Optimal feedback control as a theory of motor coordination. Nat Neurosci 5:1226-1235

Van Der Maaten L (2014) Accelerating t-SNE using tree-based algorithms. J Mach Learn Res 15(1):3221-3245

Van de Putte M, Hagemeister N, St-Onge N, Parent G, de Guise JA (2006) Habituation to treadmill walking. Biomed Mater Eng 16(1):43-52 
Vibert N, MacDougall HG, de Waele C, Gilchrist DP, Burgess AM, Sidis A, Migliaccio A, Curthoys IS, Vidal PP (2001) Variability in the control of head movements in seated humans: a link with whiplash injuries? J Physiol 532(Pt 3):851-868

Vidal PP, Vienne-Jumeau A, Moreau A, Vidal C, Wang D, Audiffren J, Ghidaglia JM (2020) An opinion paper on the maintenance of robustness: towards a multimodal and intergenerational approach using digital twins. Aging Med 3(3):188-194

Vienne-Jumeau A, Oudre L, Moreau A, Quijoux F, Edmond S, Dandrieux M, Ricard D (2020) Personalized template-based step detection from inertial measurement units signals in multiple sclerosis. Front Neurol 11:261

Vuillerme N, Danion F, Marin L, Boyadjian A, Prieur JM, Weise I, Nougier V (2001) The effect of expertise in gymnastics on postural control. Neurosci Lett 303:83-86

Wann JP, Mon-Williams M, Rushton K (1998) Postural control and coordination disorders: the swinging room revisited. Hum Mov Sci 17:491-513

Wild MR (1938) The behavior pattern of throwing and some observations concerning its course of development in children. Res Q Am Assoc Heal Phys Educ 9:20-24. https://doi.org/10.1080/23267 429.1938.11802445

Williams L, Gross J (1980) Heritability of motor skill. Acta Genet Med Gemellol 19:273-279

Winter DA (1988) The biomechanics and motor control of human gait. Waterloo Press, Waterloo

Witkin HA, Asch SE (1948) Studies in space orientation: IV. Further experiments on perception of the upright with displaced visual fields. J Exp Psychol 38:762-782

Wolff DR, Rose J, Jones VK, Bloch DA, Oehlert JW, Gamble JG (1998) Postural balance measurements for children and adolescents. J Orthop Res 16(2):271-275

Woollacott M, Debu B, Mowatt M (1987) Neuromuscular control of posture in the infant and child: is vision dominant? J Mot Behav 19(2):167-186

Wu HG, Miyamoto YR, Gonzalez Castro LN, Ölveczky BP, Smith MA (2014) Temporal structure of motor variability is dynamically regulated and predicts motor learning ability. Nat Neurosci $17: 312-321$

Wu L, Shen C, Hengel AVD (2016) Deep recurrent convolutional networks for video-based person re-identification: an end-to-end approach. arXiv: 1606.01609

Xue A, Kong R, Yang Q, Eldaief MC, Angeli PA, DiNicola LM, Braga RM, Buckner RL, Yeo BTT (2021) The detailed organization of the human cerebellum estimated by intrinsic functional connectivity within the individual. J Neurophysiol 125(2):358-384. https://doi.org/10.1152/jn.00561.2020

Yarrow K, Brown P, Krakauer JW (2009) Inside the brain of an elite athlete: the neural processes that support high achievement in sports. Nat Rev Neurosci 10(8):585-596

Yelnik AP, Kassouha A, Bonan IV, Leman MC, Jacq C, Vicaut E, Colle FM (2006) Postural visual dependence after recent stroke: assessment by optokinetic stimulation. Gait Posture 24(3):262-269

Zago M, McIntyre J, Senot P, Lacquaniti F (2009) Visuo-motor coordination and internal models for object interception. Exp Brain Res 192:571-604

Zempo H, Miyamoto-Mikami E, Kikuchi N, Fuku N, Miyachi M, Murakami H (2017) Heritability estimates of muscle strengthrelated phenotypes: a systematic review and meta-analysis. Scand J Med Sci Sports 27(12):1537-1546

Zernicke RF, Gregor RJ, Cratty BJ (1982) Balance and visual proprioception in children. J Hum Mov Stud 8:1-13

Zhang Z, Hu M, Wang Y (2011) A survey of advances in biometric gait recognition. Chinese conference on biometric recognition. Springer, Berlin, pp 150-158

Ziegler MD, Zhong H, Roy RR, Edgerton VR (2010) Why variability facilitates spinal learning. J Neurosci 30(32):10720-10726

Publisher's Note Springer Nature remains neutral with regard to jurisdictional claims in published maps and institutional affiliations. 